\title{
Pathophysiology and Imaging Diagnosis of Acute Mesenteric Ischemia
}

\author{
Claire K. Sandstrom ${ }^{1}$ \\ ${ }^{1}$ Department of Radiology, Harborview Medical Center, University of \\ Washington, Seattle, Washington \\ Address for correspondence Claire K. Sandstrom, MD, Department of \\ Radiology, Harborview Medical Center, University of Washington, 325 Ninth \\ Dig Dis Interv 2018;2:195-209. \\ Avenue, Box 359728, Seattle, WA 98104 (e-mail: cks13@uw.edu).
}

\author{
Abstract \\ Keywords \\ - mesenteric ischemia \\ - mesenteric embolism \\ - mesenteric \\ thrombosis \\ - occlusive mesenteric \\ artery disease \\ - nonocclusive \\ mesenteric ischemia \\ - mesenteric venous \\ thrombosis \\ - superior mesenteric \\ artery \\ - superior mesenteric \\ vein
}

Acute mesenteric ischemia is a potentially life-threatening condition associated with high mortality, particularly with any delay in treatment. Prompt diagnosis with imaging is crucial to achieve a favorable outcome. Both arterial and venous etiologies can result in ischemia, and the radiologist plays a central role in the initial evaluation of a patient with suspected acute mesenteric ischemia to guide management decisions. This article will review the appropriate imaging evaluation of a patient with suspected acute mesenteric ischemia. The overlapping and the distinguishing findings on imaging, as well as the relevant clinical features, will be discussed for the spectrum of both common and uncommon etiologies of mesenteric ischemia.
Acute mesenteric ischemia (AMI) is a condition of abrupt interruption in blood supply to the bowel attributed to a heterogenous group of causes. Etiologies of ischemia include arterial occlusion from a variety of underlying causes, venous occlusion, and nonocclusive arterial processes. The interruption in blood supply causes ischemia, which unreversed eventually leads to cellular damage, bowel wall necrosis, systemic inflammatory response, and death. The mortality rate ranges from 31 to $93 \%,{ }^{1-4}$ particularly when the diagnosis is delayed, ${ }^{1,2,5}$ and remains high despite advances in diagnosis and treatment. AMI increases in frequency with age, and is actually a more common cause of acute abdomen than ruptured abdominal aortic aneurysm, pancreatitis, or appendicitis in patients older than 75 years of age. ${ }^{6}$ Presenting clinical and laboratory findings are nonspecific and insensitive, ${ }^{7}$ so a high index of clinical suspicion is required to make this critical received accepted after revision June 28, 2018 published online

August 7, 2018
June 10, 2018 diagnosis as quickly as possible. Diagnosis is usually confirmed with contrast-enhanced multidetector-row computed tomography (MDCT) or angiography.

This article will discuss mesenteric anatomy, pathophysiology of acute bowel ischemia, and the differentiating clinical features and imaging appearances of the major subtypes of AMI. Management will be discussed elsewhere in this issue.

\section{Normal Anatomy and Common Variants of Mesenteric Vasculature}

After arising obliquely from the aorta at the L1 level, the superior mesenteric artery (SMA) gives off branches to the distal duodenum, the jejunum and ileum, and the ascending and transverse colon (-Fig. 1). The first branch is most often
Copyright $\odot 2018$ by Thieme Medical Publishers, Inc., 333 Seventh Avenue, New York, NY 10001, USA. Tel: +1(212) 584-4662.
DOI https://doi.org/ 10.1055/s-0038-1667344. ISSN 2472-8721.
Disorders; Guest Editors, Guy Johnson, $M D$, and Karim Valji, MD 


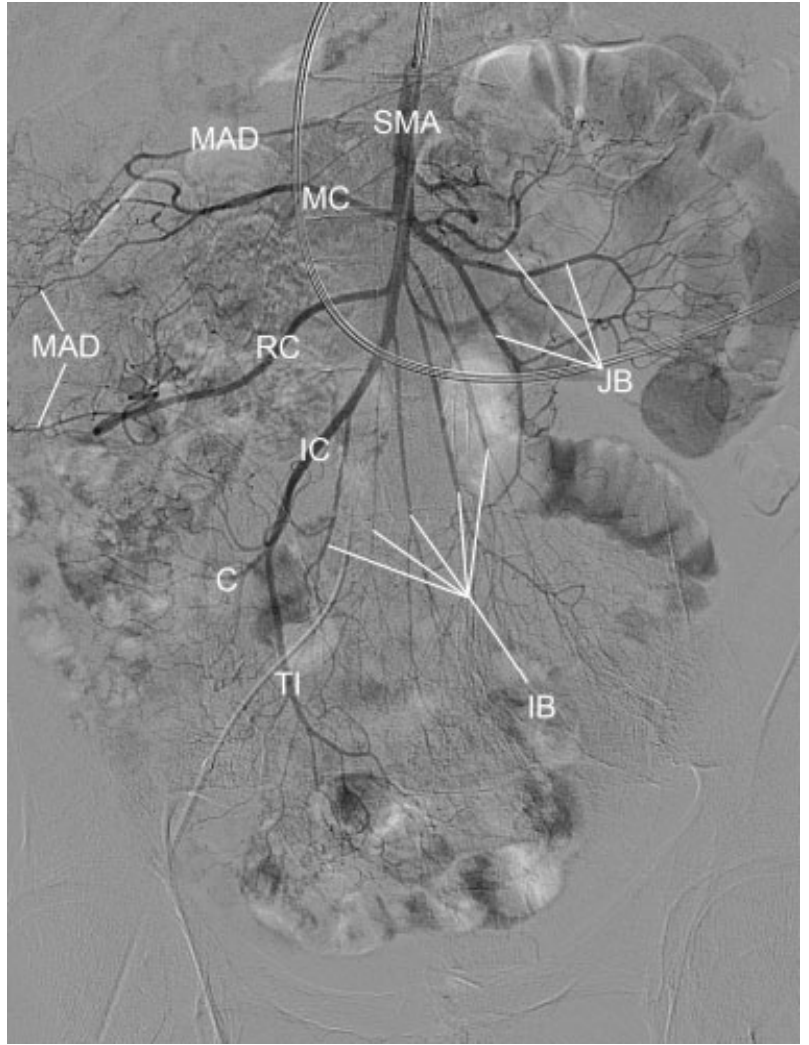

Fig. 1 Normal SMA anatomy on a digital subtraction angiogram in a 73-year-old man with lower gastrointestinal bleeding. Selective injection of the SMA shows normal arterial branching including: SMA, superior mesenteric artery; MC, middle colic artery; JB, jejunal branches; RC, right colic artery; IC, ileocolic artery; TI, terminal ileal branch; $C$, cecal branch. Portions of the marginal artery of Drummond (MAD) arise from middle colic artery and cecal branch of the ileocolic artery.

the inferior pancreaticoduodenal artery, followed next by the middle colic artery and then by multiple jejunal and ileal branches. The terminal segment of the SMA trunk is the ileocolic artery, which supplies the terminal ileum, the appendix, the cecum, and the ascending colon. Anastomoses between the SMA branches form the mesenteric arcades, which in turn give rise to the end arteries supplying the bowel wall, the vasa recta.

Additional collateral connections are present between the celiac, SMA, and inferior mesenteric artery (IMA) in most individuals. The pancreaticoduodenal arcade is formed by the inferior pancreaticoduodenal artery from the SMA and the superior pancreaticoduodenal artery from the celiac axis. Forming an arch along the mesenteric border of the entire colon, the marginal artery of Drummond is normally perfused by both the left branch of the middle colic artery from the SMA and the ascending branch of the left colic artery from the IMA, which anastomose around the level of the splenic flexure. The arc of Riolan (aka the "meandering mesenteric artery") is a central anastomosis between the proximal middle colic artery of the SMA and the proximal left colic artery of the IMA but, unlike the marginal artery of Drummond, usually only accompanies SMA or IMA stenosis or occlusion. ${ }^{8}$ Other variants in the mesenteric vasculature result from incomplete regression of the primitive fetal blood supply. ${ }^{9}$

The superior mesenteric vein (SMV) drains venous blood from the jejunum, ileum, and proximal colon and travels vertically to form the portal vein at the junction with the splenic vein (-Fig. 2). Drainage from the stomach and right colon often forms a common gastrocolic trunk before joining the SMV. ${ }^{9}$ Venous blood from the midtransverse colon to the rectum flows into the inferior mesenteric vein (IMV), which may drain into the splenic vein or SMV.

\section{Pathophysiology of Intestinal Ischemia}

The splanchnic circulation receives $25 \%$ of the cardiac output at rest and $35 \%$ after eating. ${ }^{10}$ Although a $75 \%$ reduction in blood flow can be tolerated for up to 12 hours, complete vascular occlusion will progress to irreversible intestinal infarction if untreated within 6 hours. ${ }^{10}$

Intestinal ischemia progresses through three stages..$^{11}$ Only the mucosa is affected in the first stage, resulting in increased mucosal permeability to macromolecules including albumin and intravenous contrast material. ${ }^{12}$ This may progress to mucosal and submucosal edema and even epithelial necrosis, erosions, and ulceration. ${ }^{12}$ Complete resolution is possible, however, if the ischemia is reversed at this stage. The first stage is, therefore, called reversible ischemic enteritis.

The second stage involves progressive necrosis of the underlying submucosal and muscular layers. Deeper necrosis is likely to cause luminal dilation due to either reactive interruption of peristalsis or direct muscular involvement. ${ }^{11}$ If the ischemia is reversed at this stage, a fibrotic stricture is likely to develop.

Complete transmural bowel wall necrosis indicates the third and final stage. Transmural necrosis involving

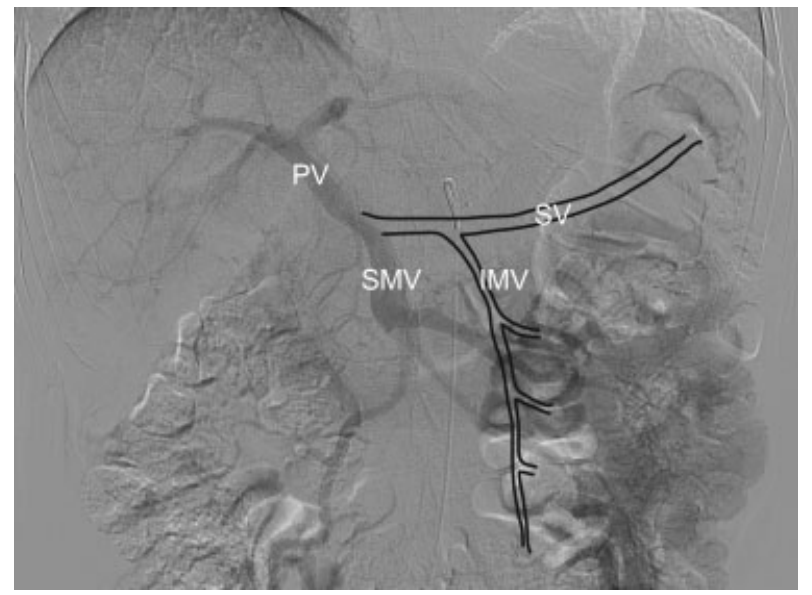

Fig. 2 Normal venous anatomy a digital subtraction portal venogram in a 69-year-old man with hepatocellular carcinoma. Delayed venogram was obtained after selective injection of the superior mesenteric artery (SMA), with opacification of the superior mesenteric vein (SMV) and the portal vein (PV). The outlined inferior mesenteric vein (IMV) and the splenic vein (SV) are not opacified because they do not drain SMA-perfused territory. 
intramural nerves and musculature results in dilated thinwalled bowel. ${ }^{11}$ Perforation is also indicative of transmural involvement, ${ }^{11}$ while pneumatosis and portal venous gas suggest an advanced stage of infarction of either partial or full wall thickness. ${ }^{13}$ Without immediate surgery, overwhelming inflammatory response, multiorgan failure, and death are likely in the third stage. ${ }^{12}$

Any stage of ischemia may be complicated by intramural hemorrhage or by superinfection of the intestinal wall. ${ }^{11}$

\section{Clinical and Laboratory Evaluation}

Most patients with AMI are elderly, and many have comorbid diseases. Most patients present with nonspecific symptoms, including abdominal pain, nausea, vomiting, and diarrhea progressing to constipation. A sudden onset of abdominal pain suggests an embolic source, while abdominal pain accompanying other forms of AMI tends to develop more insidiously. In early states, the abdominal pain is disproportionate to minimal findings on physical exam. Peritonitis, if present, is suggestive of nonviable bowel and should prompt emergent laparotomy. Fever, bloody diarrhea, and shock also suggest transmural infarction. ${ }^{14}$ Cardiovascular risk factors, such as atrial fibrillation or ischemic cardiomyopathy, are frequently present in patients with SMA embolic and atherosclerotic occlusions, respectively. ${ }^{14}$

Traditional laboratory findings are also nonspecific. ${ }^{7}$ Metabolic acidosis with elevations in lactate, $\mathrm{D}$-dimer, amylase, and circulating white blood cells can be seen. ${ }^{7}$ Recently, several novel biomarkers have been evaluated, including intestinal fatty acid-binding protein, ischemia modified albumin, $\alpha-$ glutathione $S$-transferase, D-lactate, and citrulline. ${ }^{15}$ Additional studies are needed to determine if these new biomarkers indeed have improved accuracy for the detection of AMI and to determine the optimal diagnostic thresholds. ${ }^{15}$

\section{Cross-Sectional Imaging of AMI}

Computed tomography angiography (CTA) has replaced conventional angiography in the diagnosis of AMI. CTA is recommended by the American College of Radiology (ACR) Appropriateness Criteria for rapid, noninvasive diagnosis of suspected AMI. ${ }^{16}$ A MDCT protocol that includes a combination of an arterial and a venous phase is ideal, and suggested parameters for mesenteric CTA for both single source and dual energy MDCT are given in - Table 1. ${ }^{17,18}$ However, most patients are imaged with a venous phase MDCT alone or a noncontrast MDCT, due to a low pretest clinical suspicion for AMI or due to acute renal dysfunction, respectively. In part as a result of this heterogeneity in MDCT protocols used in practice, the published range of sensitivity of MDCT is 0.66 to 0.96 and range of specificity is 0.67 to $0.98 .^{17-21}$ Subtle findings may be more easily detected with a slice thickness of 1.25 to $2.5 \mathrm{~mm} .{ }^{19}$ Maximum intensity projections, multiplanar reconstructions, and volume-rendered images may also facilitate AMI diagnosis. ${ }^{22}$ Ischemic segments may be more conspicuous on iodine maps from dual-energy MDCT, if available. ${ }^{23}$
An alternative that does not rely on radiation is magnetic resonance angiography (MRA) with gadolinium. MRA, however, is limited by lower spatial resolution, longer scan time, and inability to visualize atherosclerotic calcium. The risk of nephrogenic systemic fibrosis may also preclude administration of gadolinium to those with impaired renal function. MRA without a contrast agent is usually not appropriate due to lower sensitivity and specificity than MRA with gadolinium. ${ }^{16}$ The one scenario in which MRA may be preferred to CTA, because of the lack of ionizing radiation, is in the longitudinal evaluation of vasculitis. ${ }^{24}$

\section{Common Imaging Features of AMI}

The imaging appearance of AMI varies depending on the stage of ischemia at the time of imaging as well as the underlying etiology. Nevertheless, some common appearances can be expected on MDCT. Specific and nonspecific MDCT findings are listed in - Table 2. . $^{3,13,18,22,25,26}$ Up to one-third of patients with AMI have no specific signs of mesenteric ischemia on MDCT, although almost all will have nonspecific findings such as mesenteric fat stranding, luminal dilation, and bowel wall thickening. ${ }^{27}$ In the initial edematous stage, the bowel wall will tend to appear thickened, with either luminal dilation or spasm. As ischemia resulting from arterial occlusion without reperfusion evolves from stage one to stage three, the bowel wall tends to thin. Conversely, ischemia from a venous occlusion or after partial reperfusion may result in more severe bowel wall edema than would be expected for the stage of ischemia. ${ }^{11}$ Low attenuation of the bowel wall suggests edema, while high intramural attenuation on noncontrast imaging suggests superimposed hemorrhage. The mucosa may have absent, decreased, or increased enhancement, depending on remaining perfusion and presence of reperfusion.

Ominous signs of threatened bowel necessitating laparotomy regardless of etiology include bowel dilation with thinned wall, mucosal nonenhancement, pneumatosis, portomesenteric gas, and free air. Irreversible bowel ischemia, however, is not a diagnostic certainty even when pneumatosis and decreased bowel enhancement are present (-Fig. 3). ${ }^{26}$ In a small monocentric prospective study, three factors were predictive of irreversible bowel ischemia: organ failure, serum lactate level $>2 \mathrm{mmol} / \mathrm{L}$, and bowel luminal dilation $>2.5 \mathrm{~cm}^{28}$ Only $3 \%$ of patients with none of these three risk factors had irreversible transmural ischemia, whereas patients with 1,2 , or 3 of the factors were diagnosed with irreversible transmural ischemia at laparotomy 38,89 , and $100 \%$ of the time, respectively. ${ }^{28}$

MDCT findings that increase specificity for the underlying cause of AMI are discussed below and are summarized in - Table 3.

\section{Arterial Occlusive AMI}

Arterial occlusion is the most common cause of AMI. A variety of etiologies can result in interruption of the 
Table 1 Suggested MDCT protocols for initial diagnosis or exclusion of AMI using single source/energy MDCT and dual energy MDCT

\begin{tabular}{|c|c|c|}
\hline \multicolumn{3}{|l|}{ General MDCT preparation } \\
\hline Intravenous contrast & \multicolumn{2}{|c|}{120 mL @ 5mL/s followed by 30 mL 0.9\% NaCl IV flush @ 4mL/s } \\
\hline Oral contrast & \multicolumn{2}{|c|}{$\begin{array}{l}\text { Optional (only for outpatients and inpatients at our institution) } \\
900 \mathrm{~mL} \text { of negative oral contrast agent } \\
\text {-First } 450 \mathrm{~mL} \text { within } 15 \text { minutes } \\
\text {-Second } 450 \mathrm{~mL} \text { by } 30 \text { minutes } \\
\text {-1c water ingested on CT table at } 40 \text { minutes } \\
\text {-Scan at } 45 \text { minutes after start of oral contrast }\end{array}$} \\
\hline Scan range & \multicolumn{2}{|c|}{ Dome of diaphragm to ischial tuberosities for both arterial and venous phases } \\
\hline $\begin{array}{l}\text { For single-source/energy MDCT } \\
\text { scanning }\end{array}$ & Arterial phase & Venous phase \\
\hline Delay & $\begin{array}{l}\text { Bolus tracking at celiac axis, T11-T12. } \\
\text { Peak plus } 11 \text { seconds }\end{array}$ & $\begin{array}{l}\text { Fixed delay, } \\
\sim 70 \text { seconds after start of contrast }\end{array}$ \\
\hline Scan energy & $120 \mathrm{KV}$ & $120 \mathrm{KV}$ \\
\hline Acquired slice thickness & $0.6 \mathrm{~mm}$ & $0.6 \mathrm{~mm}$ \\
\hline Pitch & 0.9 & 1.2 \\
\hline Rotation & 0.3 & 0.5 \\
\hline Multiplanar reconstructions (MPR) & $\begin{array}{l}\text { 1. Axial ( } 3 \mathrm{~mm} \text { slice thickness) } \\
\text { 2. Coronal ( } 3 \mathrm{~mm} \text { slice thickness) } \\
\text { 3. Sagittal upon request by radiologist }\end{array}$ & $\begin{array}{l}\text { 1. Axial ( } 3 \mathrm{~mm} \text { slice thickness) } \\
\text { 2. Coronal ( } 3 \mathrm{~mm} \text { slice thickness) } \\
\text { 3. Sagittal upon request by radiologist }\end{array}$ \\
\hline $\begin{array}{l}\text { Maximum intensity projection (MIP) } \\
\text { reconstructions }\end{array}$ & $\begin{array}{l}\text { 4. Sagittal (10mm slice thickness, } 1 \mathrm{~mm} \\
\text { increment) }\end{array}$ & None standard \\
\hline Three-dimensional reconstruction & 5. Horizontal rotation of entire aorta & None standard \\
\hline For dual-energy MDCT scanning & Arterial phase & Venous phase \\
\hline Delay & $\begin{array}{l}\text { Bolus tracking at celiac axis, T11-T12 } \\
\text { Peak plus } 11 \text { seconds }\end{array}$ & $\begin{array}{l}\text { Fixed delay, } \sim 70 \text { seconds after start of } \\
\text { contrast }\end{array}$ \\
\hline Scan energy & $90 / S n 150 \mathrm{KV}$ & $120 \mathrm{KV}$ (single energy) \\
\hline Acquired slice thickness & $0.6 \mathrm{~mm}$ & $0.6 \mathrm{~mm}$ \\
\hline Pitch & 0.9 & 1.2 \\
\hline Rotation & 0.28 & 0.5 \\
\hline MPR & $\begin{array}{l}\text { 1. Axial ( } 2 \mathrm{~mm} \text { slice thickness) } \\
\text { 2. Coronal ( } 3 \mathrm{~mm} \text { slice thickness) } \\
\text { 3. Sagittal upon request by Radiologist } \\
\text { 4. Axial mono-energetic } 45 \mathrm{KEV} \text { ( } 3 \mathrm{~mm} \\
\text { slice thickness) } \\
\text { 5. Virtual noncontrast ( } 3 \mathrm{~mm} \text { slice thick- } \\
\text { ness, dual energy composition of } 0.6 \text { ) }\end{array}$ & $\begin{array}{l}\text { 1. Axial ( } 2 \mathrm{~mm} \text { slice thickness) } \\
\text { 2. Coronal ( } 3 \mathrm{~mm} \text { slice thickness) } \\
\text { 3. Sagittal upon request by radiologist }\end{array}$ \\
\hline $\begin{array}{l}\text { MIP } \\
\text { reconstructions }\end{array}$ & $\begin{array}{l}\text { 6. Sagittal ( } 16 \mathrm{~mm} \text { slice thickness, } \\
3 \mathrm{~mm} \text { increment) } \\
\text { 7. Coronal ( } 16 \mathrm{~mm} \text { slice thickness, } 3 \mathrm{~mm} \\
\text { increment) }\end{array}$ & None standard \\
\hline Three-dimensional reconstruction & 8. Horizontal rotation of entire aorta & None standard \\
\hline
\end{tabular}

Abbreviations: AMI, acute mesenteric ischemia; MDCT, multidetector-row computed tomography

mesenteric arterial inflow, the most common being embolization and atherosclerotic occlusion, while less common causes include dissection, vasculitis or vasculopathy, and trauma. Extrinsic compression such as from closed loop bowel obstruction or volvulus can also cause arterial obstruction, although venous obstruction tends to precede this and dominates the imaging appearance, and thus these entities will be discussed in the section on venous occlusion.

\section{Mesenteric Arterial Embolism}

Emboli resulting in acute SMA occlusion are usually cardiogenic in origin. ${ }^{29}$ Although embolic infarcts can be seen in multiple organs, the SMA is particularly susceptible to embolization due to its oblique origin and high flow rate. ${ }^{30}$ The location, degree, and duration of vascular occlusion and the presence of reperfusion will affect the stage and extent of ischemia. Most often, the embolus is identified 3 to $8 \mathrm{~cm}$ 
Table 2 Specific and nonspecific findings of AMI on MDCT

\begin{tabular}{|c|}
\hline $\begin{array}{l}\text { Findings nonspecific for AMI on CTA or MDCT venous } \\
\text { phase: }\end{array}$ \\
\hline $\begin{array}{l}\text {-Isolated BWT }>3 \mathrm{~mm} \text { (measured at noncollapsed } \\
\text { small bowel or colon perpendicular to transverse } \\
\text { plane) }\end{array}$ \\
\hline -Isolated stratification of bowel wall (target sign) \\
\hline $\begin{array}{l}\text {-Isolated bowel lumen dilation (small bowel }>2.5 \mathrm{~cm} \text {, } \\
\text { colon }>8 \mathrm{~cm} \text { ) }\end{array}$ \\
\hline $\begin{array}{l}\text {-Transition point between dilated proximal and collapsed } \\
\text { distal bowel }\end{array}$ \\
\hline -Mesenteric stranding \\
\hline -Ascites \\
\hline Findings specific for AMI on CTA or MDCT venous phase: \\
\hline Bowel findings: \\
\hline -BWT + Focally absent bowel wall enhancement \\
\hline -BWT + Focally decreased bowel wall enhancement \\
\hline -BWT + Focally increased bowel wall enhancement \\
\hline $\begin{array}{l}\text {-BWT + Target sign (submucosal edema + mucosal } \\
\text { hyper-enhancement) }\end{array}$ \\
\hline $\begin{array}{l}\text { Late signs of partial- or full-thickness bowel ischemia } \\
\text { (although damage may still be reversible): }\end{array}$ \\
\hline -Pneumatosis intestinalis \\
\hline -Venous gas \\
\hline $\begin{array}{l}\text { Late signs of ischemia suggesting transmural bowel } \\
\text { necrosis: }\end{array}$ \\
\hline -Free intraperitoneal or retroperitoneal gas \\
\hline $\begin{array}{l}\text {-Bowel wall thinning }+ \text { Focally absent bowel wall } \\
\text { enhancement }\end{array}$ \\
\hline $\begin{array}{l}\text { Ancillary findings that should prompt more careful } \\
\text { assessment for AMI: }\end{array}$ \\
\hline -SMA occlusion \\
\hline -Atherosclerotic disease of SMA + celiac/IMA \\
\hline $\begin{array}{l}\text {-Mesenteric whirl sign, venous cut-off sign, bowel } \\
\text { obstruction }\end{array}$ \\
\hline -SMA dissection flap \pm aneurysmal dilation \\
\hline -Thoracoabdominal aortic dissection \\
\hline -SMV venous thrombosis \\
\hline $\begin{array}{l}\text {-Solid organ infarction (including spleen, kidney, } \\
\text { and brain) }\end{array}$ \\
\hline $\begin{array}{l}\text {-Left atrial or ventricular thrombus or valvular vegetation/ } \\
\text { thrombus }\end{array}$ \\
\hline -Circumferential or eccentric wall thickening of SMA \\
\hline -Diffusely small SMA \pm irregular SMA narrowing \\
\hline $\begin{array}{l}\text {-Free fluid, mesenteric hematoma, irregularity/ } \\
\text { termination of mesenteric vessels in the setting of } \\
\text { abdominal trauma }\end{array}$ \\
\hline
\end{tabular}

Abbreviations: AMI, acute mesenteric ischemia; BWT, bowel wall thickening; CTA, computed tomography angiography; IMA, inferior mesenteric artery; IMV, inferior mesenteric vein; MDCT, multidetector computed tomography; SMA, superior mesenteric artery; SMV, superior mesenteric vein. distal to the SMA ostium, where vascular arborization results in a natural luminal narrowing (-Fig. 4). ${ }^{31}$ The jejunum and transverse colon are spared from ischemia if the embolus lodges distal to the first jejunal branches and middle colic artery. $^{32}$ The embolus may have a convex proximal surface. Intracardiac thrombi may be identified by MDCT or echocardiogram.

\section{Atherosclerotic Mesenteric Arterial Occlusive Disease without or with Thrombosis}

Occlusion of the SMA by atherosclerotic disease is historically the second most common cause of AMI, and may now be the most common cause, particularly in the elderly. ${ }^{26}$ SMA luminal stenosis is found in $2 \%$ of patients aged 70 years and older, and of those, 50 to $80 \%$ will also have celiac artery stenosis. ${ }^{26}$ Chronic mesenteric ischemia may be considered when characteristic chronic symptoms (postprandial abdominal pain that resolves spontaneously, food avoidance, weight loss) accompany imaging findings of stenotic atherosclerotic disease of at least two of the mesenteric arteries. ${ }^{30}$ Collateral vessels, such as the arc of Riolan, may be seen with chronic high-grade stenosis and may help protect against AMI.

Superimposed AMI occurs when a sudden critical blockage complicates pre-existing chronic multivessel stenosis or occlusion-this is classically attributed to acute thrombosis (-Fig. 5), although mesenteric hypoperfusion or progressive nonthrombotic plaque can also occur without MDCT evidence of acute thrombosis (- Fig. 6). ${ }^{21,26}$ Atherosclerotic plaque tends to form at the ostium, and thus the occlusion usually occurs at the ostium or within 2 to $3 \mathrm{~cm}$ of the SMA origin. The occlusion is typically more proximal than that seen with SMA embolization, and is thus more likely to involve the jejunum and transverse colon. ${ }^{29,31}$ Differentiation of symptomatic acute-on-chronic mesenteric ischemia from a different source of acute abdominal pain with an asymptomatic SMA stenosis can be difficult, although mesenteric fat stranding, small bowel lumen dilation, and small bowel wall thickening are rare in chronic mesenteric ischemia.

\section{Mesenteric Arterial Dissection}

SMA dissection can be primary 33,34 or secondary. ${ }^{35}$ Secondary mesenteric dissection is contiguous with a type A or type B aortic dissection (-Fig. 7), and the prognosis of aortic dissection is worsened if accompanied by mesenteric ischemia. ${ }^{36}$ Primary or spontaneous SMA dissection, which is not associated with aortic dissection, classically begins 1.5 to $3 \mathrm{~cm}$ beyond the SMA origin along the anterior vessel wall (-Fig. 8). ${ }^{33}$ While often idiopathic, ${ }^{33}$ some spontaneous SMA dissections may originate within aneurysms of segmental arterial mediolysis (SAM). ${ }^{37}$

\section{Mesenteric Artery Vasculitis and Vasculopathy}

Although rare and more often presenting with chronic mesenteric ischemia, several collagen vascular diseases and inflammatory vasculitides have been associated with AMI, including Behçet's disease, Takayasu arteritis, giant cell 

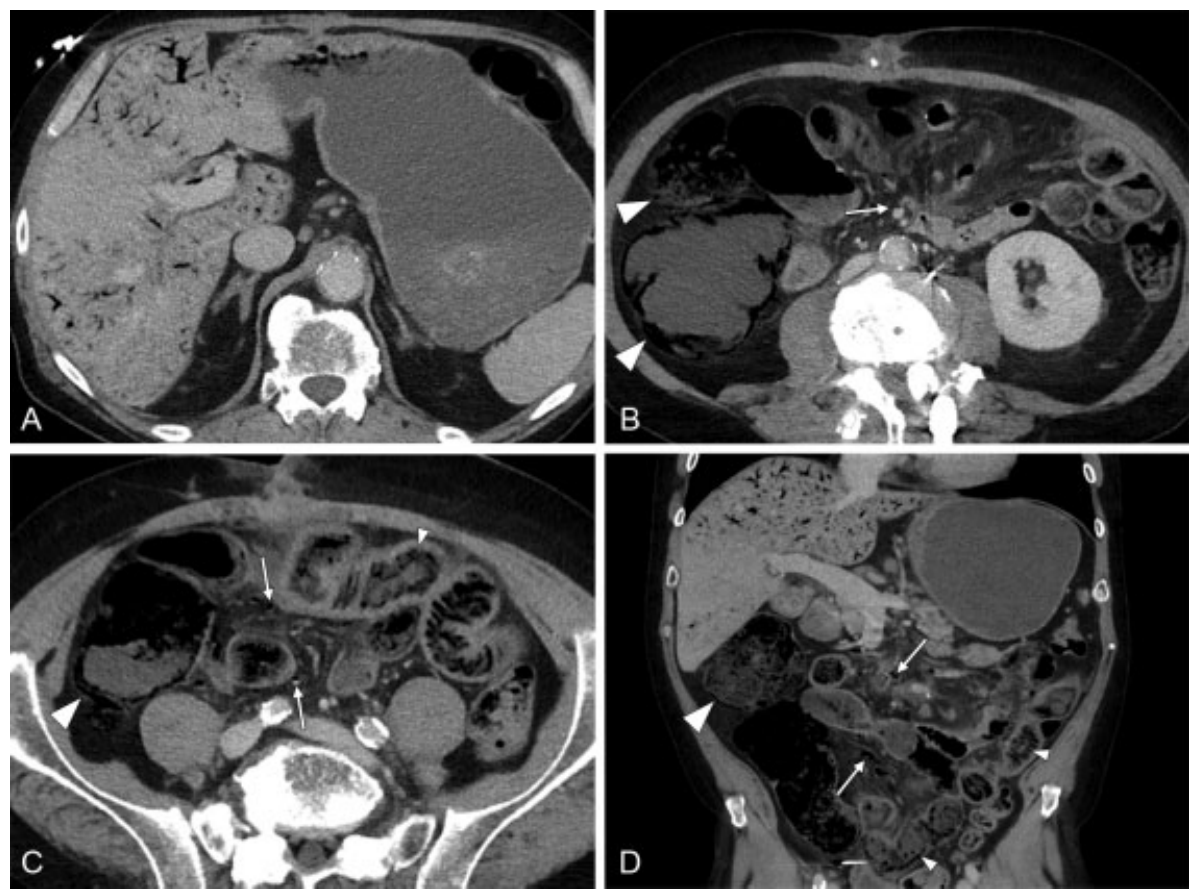

Fig. 3 Reversible bowel ischemia in a 66-year-old man. He presented with 2 days of abdominal pain and melena; he reported a remote history of testicular cancer status postchemoradiation. (A-C) Axial and (D) coronal images from contrast-enhanced computed tomography show extensive portal venous gas, superior mesenteric vein (SMV) gas (white arrows), diffuse mesenteric stranding, cecal pneumatosis (large white arrowheads) and distal small bowel wall thickening, hyperenhancement, and pneumatosis (small white arrowheads). The superior mesenteric artery (SMA) lumen was obscured by surgical clips from retroperitoneal dissection, but atherosclerotic plaque was definitely present. This patient was admitted and started on antibiotics and heparin but never demonstrated peritoneal signs. Gradually, his abdominal pain, leukocytosis of 17,000, and lactate of 1.5 trended toward normal, and his abdominal pain and tenderness resolved without need for either endovascular or surgical intervention. An echocardiogram was negative for thromboembolic source, and he was discharged to home with a presumptive diagnosis of acute mesenteric ischemia from atherosclerotic disease.

arteritis, polyarteritis nodosa, systemic lupus erythematosus, Buerger's disease, and radiation-induced vasculitis. ${ }^{38-46}$ Unfortunately, treatment of inflammatory vasculitis with steroids can both increase the risk of gastrointestinal problems and delay detection of intraperitoneal complications. General MDCT signs of vasculitis include stenosis, often over a long segment without calcification or irregularity characteristic of atherosclerosis (- Fig. 9), vascular occlusion, vascular wall thickening and enhancement, perivascular inflammation, and aneurysm. ${ }^{40}$ On MDCT in practice, wall thickening from vasculitis can be difficult to differentiate from a dissection with thrombosed false lumen.

SAM is a noninflammatory, nonatherosclerotic vasculopathy that characteristically affects the mesenteric arteries. SAM tends to present in late middle-age and elderly patients with spontaneous hemorrhage or acute luminal occlusion. ${ }^{47}$ Although a rare diagnosis, SAM most commonly involves the mesenteric arteries, with renal and iliac arterial involvement also seen. ${ }^{37}$ Dissecting aneurysms are the classic manifestation (-Fig. 10), resulting when cavitation within the outer portion of the arterial wall media leads to mural weakening, dissection, and pseudoaneurysm formation. ${ }^{37,47}$ Circumferential or partial wall multifocal segmental involvement may be seen, with alternating stenotic and aneurysmal portions. Unrecognized SAM may underlie some cases of spontaneous SMA dissection. ${ }^{37}$
SAM overlaps in imaging and histologic features with fibromuscular dysplasia (FMD), although mesenteric involvement by FMD is rare. FMD is typically detected in young females and more frequently affects the renal and internal carotid arteries.

\section{Mesenteric Trauma}

Traumatic SMA injuries are caused by penetrating injuries more often than by blunt trauma. ${ }^{48}$ In the American Association for the Surgery of Trauma-Organ Injury Scale for Abdominal Vascular Injury, injuries involving the IMA, IMV, or primary named branches of the SMA or SMV are Grade II; SMV trunk injuries are Grade III; and SMA trunk injuries are Grade IV. ${ }^{49}$ Mortality rates range from 23 to $77 \%$ based on peripheral versus central location of the arterial injury (according to the zonal designations described by Fullen et $\left.\mathrm{al}^{50}\right) .48$ Injuries proximal to the inferior pancreaticoduodenal branch are associated with the highest mortality (77\%), whereas relatively low mortality rates are seen with injuries to the SMA trunk distal to the middle colic artery (28\%) or with injuries of segmental jejunal, ileal, or colic branches (23\%). ${ }^{48,50,51}$ Exsanguination accounts for the majority of early deaths, reflecting the difficulty in obtaining control of the injured mesenteric artery and back-bleeding from the valveless portomesenteric system. ${ }^{48,52}$ Delayed deaths are usually attributed to bowel ischemia, sepsis, and multiple organ failure. ${ }^{48}$ 
Table 3 Overview of causes of acute mesenteric ischemia

\begin{tabular}{|c|c|c|c|}
\hline Source & $\begin{array}{l}\text { Vascular } \\
\text { location }\end{array}$ & Characteristic imaging findings & Clinical features \\
\hline \multicolumn{4}{|l|}{ Arterial occlusion } \\
\hline Embolic occlusion & $\begin{array}{l}3-8 \mathrm{~cm} \text { distal to } \\
\text { SMA origin }\end{array}$ & $\begin{array}{l}\text {-Convex proximal border } \\
\text {-Often spares jejunum and transverse colon }\end{array}$ & $\begin{array}{l}\text {-Very acute clinical course } \\
\text {-Emboli most often cardiogenic }\end{array}$ \\
\hline $\begin{array}{l}\text { Atherosclerotic } \\
\text { occlusion }\end{array}$ & $\begin{array}{l}\text { SMA ostium or } \\
\text { proximal } 2-3 \mathrm{~cm} \\
\text { of SMA }\end{array}$ & $\begin{array}{l}\text {-Calcified atherosclerotic plaque } \\
\text {-Jejunum and transverse colon usually } \\
\text { involved }\end{array}$ & $\begin{array}{l}\text {-Atherosclerotic stenotic or occlusive disease } \\
\text { of SMA, celiac, and/or IMA (usually } \geq 2 \text { ) } \\
\text {-Collateral vessels } \\
\text {-Symptoms of chronic mesenteric ischemia }\end{array}$ \\
\hline $\begin{array}{l}\text { Secondary } \\
\text { mesenteric } \\
\text { dissection }\end{array}$ & $\begin{array}{l}\text { Always arises } \\
\text { from the aortic } \\
\text { lumen, variable } \\
\text { length of SMA } \\
\text { involvement }\end{array}$ & $\begin{array}{l}\text {-Continuous with type A or B aortic } \\
\text { dissection }\end{array}$ & $\begin{array}{l}\text {-Abdominal pain or other clinical signs of } \\
\text { mesenteric ischemia WITH clinical signs of } \\
\text { thoracic aortic dissection }\end{array}$ \\
\hline $\begin{array}{l}\text { Spontaneous } \\
\text { mesenteric } \\
\text { dissection }\end{array}$ & $\begin{array}{l}\text { Anterior wall of } \\
\text { proximal SMA } \\
\text { curve }\end{array}$ & $\begin{array}{l}\text {-No aortic dissection } \\
\text {-Look for accompanying aneurysms or } \\
\text { additional dissections suggestive of seg- } \\
\text { mental arterial mediolysis }\end{array}$ & $\begin{array}{l}\text {-May be idiopathic without antecedent } \\
\text { trauma or traditional risk factors for } \\
\text { dissection }\end{array}$ \\
\hline $\begin{array}{l}\text { Vasculitis or col- } \\
\text { lagen } \\
\text { vascular disorders }\end{array}$ & $\begin{array}{l}\text { Depends on type } \\
\text { of vasculopathy } \\
\text { (large, medium, } \\
\text { or small vessel) }\end{array}$ & $\begin{array}{l}\text {-Vascular wall thickening and enhance- } \\
\text { ment, low intramural attenuation on } \\
\text { delayed images, perivascular inflamma- } \\
\text { tion, stenosis or occlusion without classic } \\
\text { features of atherosclerosis, aneurysms }\end{array}$ & $\begin{array}{l}\text {-Steroid treatment of underlying inflamma- } \\
\text { tory condition may increase risk of gastro- } \\
\text { intestinal complications and suppress } \\
\text { clinical signs of bowel ischemia or necrosis }\end{array}$ \\
\hline $\begin{array}{l}\text { Mesenteric } \\
\text { vascular trauma }\end{array}$ & $\begin{array}{l}\text { Variable from } \\
\text { proximal to distal } \\
\text { arteries and/or } \\
\text { veins }\end{array}$ & $\begin{array}{l}\text {-Free fluid or mesenteric hematoma }+/- \\
\text { active extravasation } \\
\text {-beaded irregularity or abrupt termination } \\
\text { of mesenteric vessels } \\
\text {-Focal bowel wall thickening and abnormal } \\
\text { enhancement }\end{array}$ & $\begin{array}{l}\text {-Laparotomy indicated if direct MDCT signs } \\
\text { of mesenteric vascular injury, bowel ische- } \\
\text { mia, or bowel injury } \\
\text {-Hypoperfusion complex = diffuse bowel } \\
\text { hyperenhancement and mural thickening } \\
\text { + flat IVC }+ \text { - - peripancreatic fluid, aberrant } \\
\text { enhancement of abdominal solid organs }\end{array}$ \\
\hline \multicolumn{4}{|l|}{ Venous occlusion } \\
\hline $\begin{array}{l}\text { Mesenteric } \\
\text { venous } \\
\text { thrombosis }\end{array}$ & $\begin{array}{l}\text { SMV thrombosis } \\
\text { with variable } \\
\text { involvement of } \\
\text { portal vein, sple- } \\
\text { nic vein, and/or } \\
\text { small peripheral } \\
\text { venous arcades, } \\
\text { although AMI is } \\
\text { more likely with } \\
\text { peripheral } \\
\text { involvement }\end{array}$ & $\begin{array}{l}\text { Expanded, occluded mesenteric vein(s), } \\
\text { hyperdense venous clot } \\
\text {-Bowel wall thickening and indistinctness, } \\
\text { mesenteric infiltration, and ascites } \\
\text {-Thrombophlebitis more likely if ring } \\
\text { enhancement of venous wall, gas within } \\
\text { clot, intrahepatic abscess(es) }\end{array}$ & $\begin{array}{l}\text { - Hypercoagulable state, direct venous injury, } \\
\text { or local venous stasis/congestion present in } \\
\text { about half of cases } \\
\text {-Consider intra-abdominal inflammatory } \\
\text { process (appendicitis, diverticulitis, etc.) as } \\
\text { cause of thrombosis / thrombophlebitis }\end{array}$ \\
\hline $\begin{array}{l}\text { Strangulated } \\
\text { bowel } \\
\text { obstruction }\end{array}$ & $\begin{array}{l}\text { Intramural } \\
\text { vessels }\end{array}$ & $\begin{array}{l}\text {-Signs of bowel obstruction (luminal dila- } \\
\text { tion, focal transition point), PLUS noncon- } \\
\text { trast bowel wall hyperdensity and } \\
\text { decreased bowel wall enhancement } \\
\text {-Ascites and mesenteric stranding }\end{array}$ & -Most often from postoperative adhesions \\
\hline $\begin{array}{l}\text { Volvulus and/or } \\
\text { closed loop } \\
\text { obstruction }\end{array}$ & $\begin{array}{l}\text { Point of conver- } \\
\text { gence / volvulus } \\
\text { Venous obstruc- } \\
\text { tion }>\text { arterial } \\
\text { obstruction }\end{array}$ & $\begin{array}{l}\text { Venous cut-off sign, whirl sign } \\
\text {-U-shaped segment of dilated bowel }+/- \\
\text { upstream bowel dilation } \\
\text {-Two transition points in close approxima- } \\
\text { tion, each with triangular cross-section }\end{array}$ & $\begin{array}{l}\text {-Congenital malrotation and internal hernia } \\
\text { are important to consider }\end{array}$ \\
\hline \multicolumn{4}{|l|}{ Nonocclusive cause } \\
\hline $\begin{array}{l}\text { Non-occlusive } \\
\text { mesenteric } \\
\text { ischemia }\end{array}$ & $\begin{array}{l}\text { No vascular } \\
\text { occlusion }\end{array}$ & $\begin{array}{l}\text {-Signs of bowel ischemia/infarct, }+/ \text { - } \\
\text {-Irregular SMA narrowing (string of sau- } \\
\text { sages), spasm of visceral arcades }\end{array}$ & $\begin{array}{l}\text {-Critically ill patients with septic shock, } \\
\text { hypovolemic or hemorrhagic shock, cardio- } \\
\text { genic shock, vasoconstrictor administra- } \\
\text { tion, and/or use of vasoactive drugs } \\
\text {-Use of vasoconstrictors to maintain sys- } \\
\text { temic blood pressure likely to exacerbate } \\
\text { mesenteric malperfusion }\end{array}$ \\
\hline
\end{tabular}

Abbreviations: AMI, acute mesenteric ischemia; IMA, inferior mesenteric artery; IVC, inferior vena cava; MDCT, multidetector-row computed tomography; SMA, superior mesenteric artery; SMV, superior mesenteric vein. 

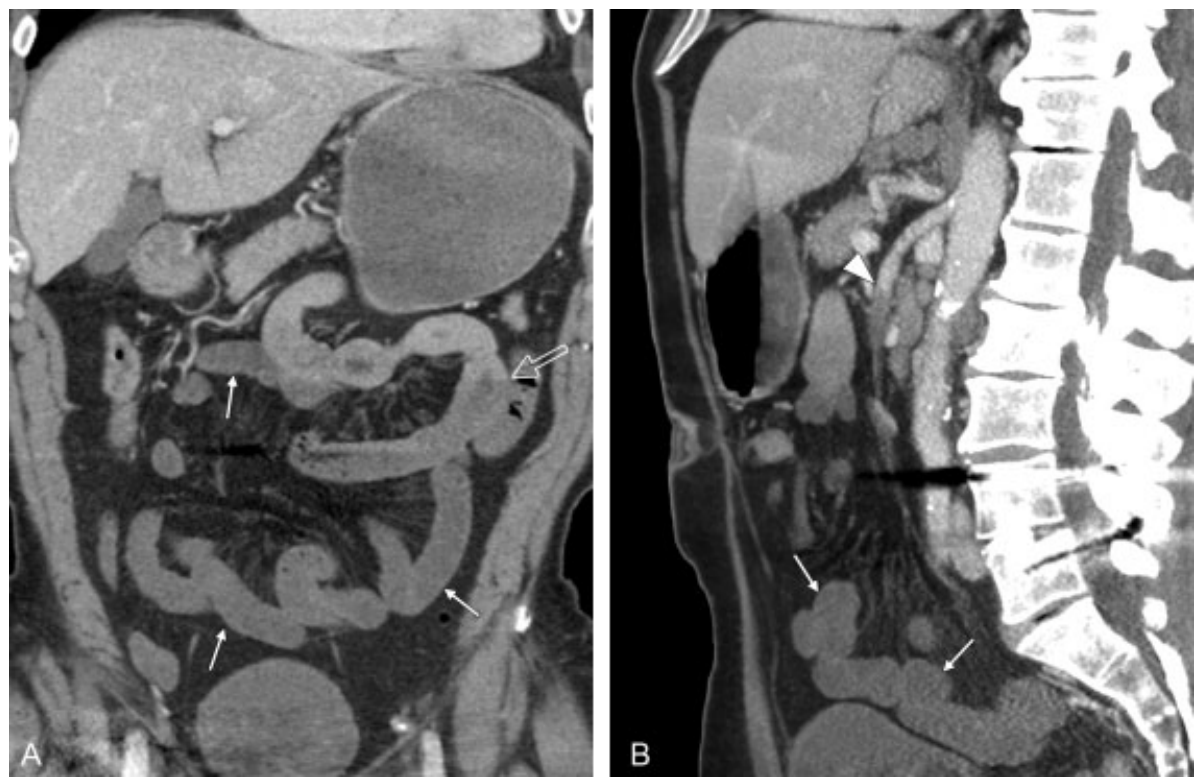

Fig. 4 Superior mesenteric artery (SMA) thromboembolism in a 74-year-old man. He had a history of atrial fibrillation but recently stopped anticoagulation after an upper gastrointestinal bleed attributed to an adenocarcinoma at the gastroesophageal junction. He developed sudden onset of abdominal pain at $6 \mathrm{pm}$ and underwent venous phase abdominopelvic computed tomography (CT) at $11 \mathrm{pm}$. (A) Coronal image and (B) sagittal maximum intensity projection image show diffusely decreased enhancement of the ileum and jejunum (white arrows), with an abrupt transition point (open arrow) in the left abdomen. There is occlusion of the mid-SMA (arrowhead) without evidence of underlying atherosclerosis. No specific CT findings of bowel infarct. Laparotomy that night showed dusky bowel but no frank ischemia, and vascular surgery performed a thromboembolectomy.

While the absence of free fluid on MDCT excludes bowel or mesenteric injury, ${ }^{53}$ the presence of moderate-to-large volume of free fluid following abdominal trauma is highly sensitive for bowel or mesenteric injury. The fluid may reflect blood products and/or extraluminal bowel contents. Free fluid in isolation, though, is nonspecific, particularly if solid organ or bladder injury is also present. High suspicion for mesenteric injury should be raised if MDCT reveals beaded irregularity or abrupt termination of mesenteric vessels (-Fig. 11), even without active bleeding. ${ }^{53}$ Active mesenteric hemorrhage indicates significant mesenteric injury that requires laparotomy. ${ }^{54}$

Both bowel wall injuries and bowel wall ischemia can manifest as nonspecific segmental bowel wall thickening and abnormal enhancement on MDCT. ${ }^{53}$ Bowel injury or bowel ischemia secondary to mesenteric injury will generally be focal, whereas diffuse mucosal hyperenhancement and bowel wall thickening suggest splanchnic hypoperfusion (in other words, nonocclusive mesenteric ischemia (NOMI), discussed in a later section) secondary to hypovolemic shock. ${ }^{54}$ Splanchnic hypoperfusion as part of the post-traumatic hypoperfusion complex, first described in children ${ }^{55}$ and later in adults, ${ }^{56}$ is often accompanied by flattened inferior vena cava (IVC) and renal veins, fluid surrounding the intrahepatic IVC and pancreas, and aberrations in intraabdominal solid organ enhancement (increased or decreased). ${ }^{55,56}$ Patients with hypoperfusion complex generally only require resuscitation after control of hemorrhage,
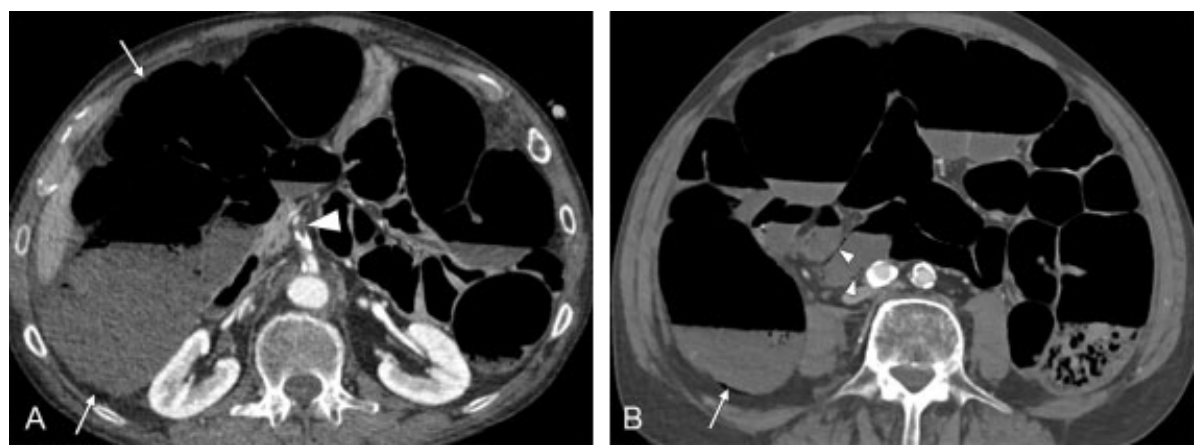

Fig. 5 Acute superior mesenteric artery (SMA) thrombosis in a 59-year-old man. After developing left lower quadrant abdominal pain and abdominal distension, he underwent a dual-energy contrast-enhanced computed tomography. (A-B) Axial images show atherosclerotic calcification with focal thrombotic occlusion (large arrowhead) of the proximal SMA and signs of intestinal ischemia including dilation, pneumatosis, wall thinning, and hypoenhancement of right-sided colon (arrows) and small bowel loops (small arrowheads). Emergent laparotomy revealed necrosis of the entire ileum, most of the jejunum, and cecum, ascending and transverse colon. 

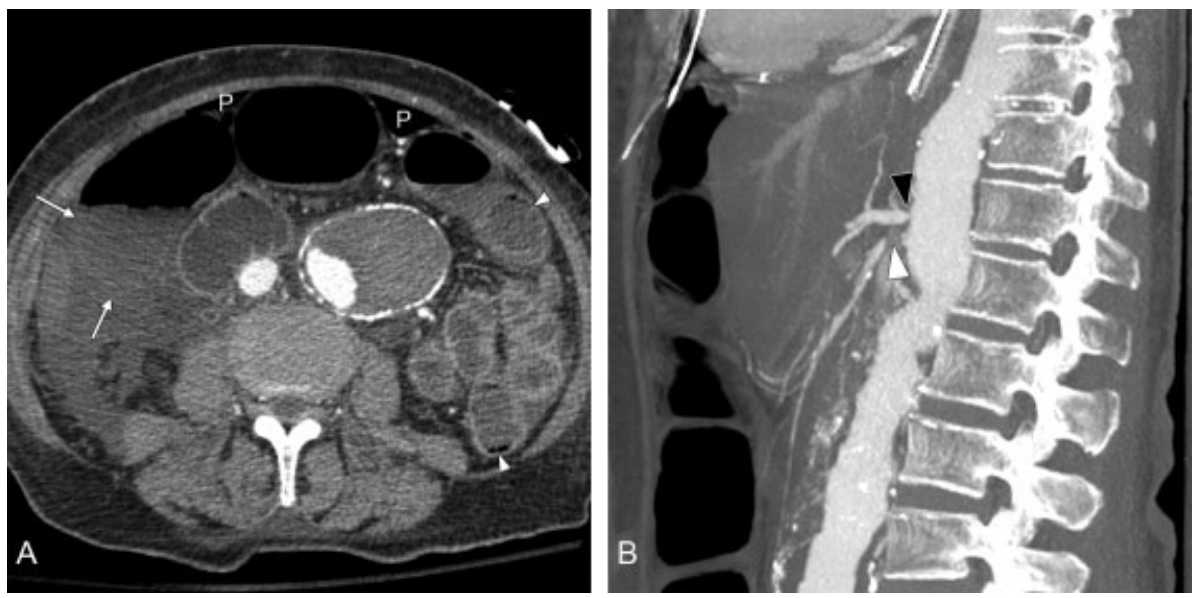

Fig. 6 Acute mesenteric ischemia superimposed on chronic superior mesenteric artery (SMA) and celiac atherosclerotic occlusion in a 70-yearold woman with known thoracoabdominal aortic aneurysm. She complained of several months of weight loss and fear of food. After undergoing coronary artery bypass grafting, the patient was noted to have rising lactate. (A) Axial image from contrast-enhanced computed tomography shows hypoenhancement of the right colon (arrows), pneumoperitoneum (P), and possible pneumatosis involving left-sided bowel loops (small arrowheads). (B) Sagittal maximum intensity projection image shows high-grade stenosis of the celiac artery origin (black arrowhead) and chronic short-segment occlusion of the SMA (white arrowhead). The inferior mesenteric artery (not shown) was also occluded at the origin. No acute thrombosis was detected. At emergent laparotomy, the right colon was frankly necrotic and was removed. Interventional radiology was able to place a stent across the SMA stenosis, but the patient ultimately succumbed to multiple organ failure.

while direct bowel injuries and AMI-producing mesenteric injuries require laparotomy.

\section{AMI from Venous Occlusion}

Mesenteric venous outflow obstruction causes congestion of bowel, and if not relieved, can progress to ischemia and infarct. The most common venous cause of AMI is mesenteric venous thrombosis (MVT). Volvulus and closed loop obstruction can also cause AMI, which is at least initially secondary to venous compression, although arterial occlusion can also be seen.

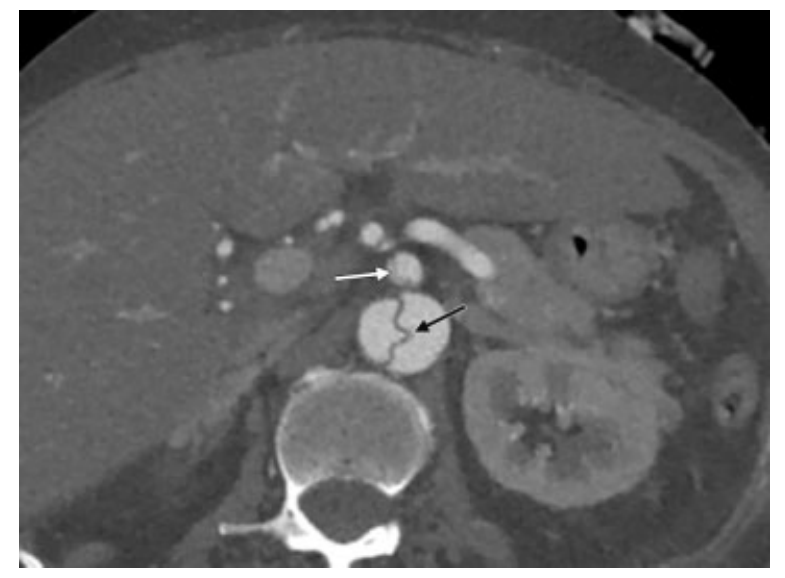

Fig. 7 Secondary superior mesenteric artery (SMA) dissection in a 70year-old woman with Stanford type B aortic dissection. Axial image from computed tomography angiography shows contrast in the true and false lumina outlining the dissection flap (black arrow) in the thoracoabdominal aorta. The dissection extends into the SMA (white arrow). There was no clinical or imaging evidence of SMA occlusion or mesenteric ischemia.

\section{Mesenteric Venous Thrombosis}

About one-sixth of cases of AMI are the result of impaired venous outflow from MVT. ${ }^{29}$ Involvement of the SMV, splenic vein, and portal vein is common, while IMV thrombosis is rare. ${ }^{57}$ In contradistinction to the often sudden and acute presentation of arterial occlusion, the presentation of MVT is more insidious. Thrombus location, extent, and speed of propagation will determine the extent and severity of subsequent ischemia. Peripheral MVT is likely to cause early ischemia, whereas isolated portal vein thrombosis is usually subclinical until complicated by portal hypertension from chronic venous thrombosis. ${ }^{57}$ Isolated portal vein thrombosis is unlikely to cause AMI. Although up to half of cases remain idiopathic, ${ }^{57,58}$ MVT has been associated with numerous conditions. These include inherited and acquired hypercoagulability, including thrombophilia, malignancy, and oral contraceptive use; concurrent or prior extramesenteric venous thromboembolic disease; direct venous injury from intra-abdominal inflammatory conditions, abdominal trauma, or iatrogenia; local venous stasis or congestion; and morbid obesity. ${ }^{29}$

On contrast-enhanced MDCT, a well-defined tubular hypodensity along the expected course of a mesenteric vein is suggestive of thrombus (-Fig. 12). A potential mimic is mixing artifact, which is generally less well defined and will resolve with more delayed imaging. If MDCT is performed without contrast, a thrombosed venous segment may appear hyperdense, particularly when narrow windows are used. ${ }^{59}$ Although a line, crescent, or ring of contrast may be seen within the vein lumen adjacent to a nonocclusive bland thrombus, a finding of circumferential vessel wall enhancement suggests thrombophlebitis. Thrombophlebitis of the portal system (also known as pylephlebitis) may also manifest with gas in or adjacent to the thrombus and intrahepatic abscess formation. ${ }^{60}$ Both bland 

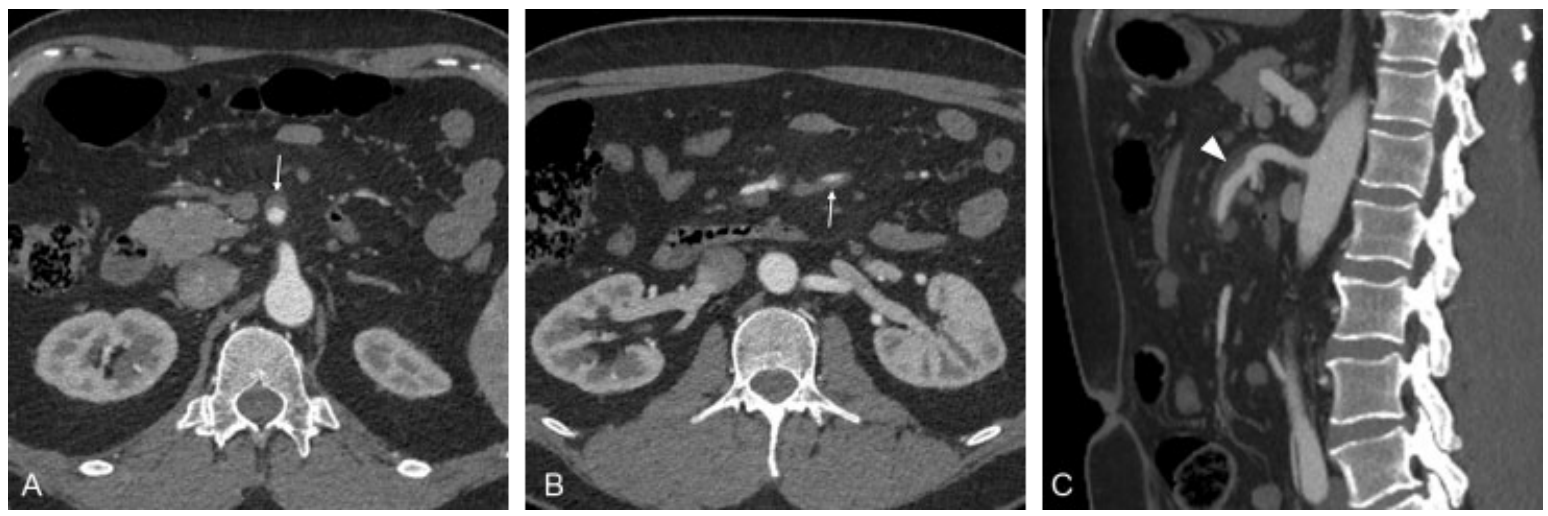

Fig. 8 Spontaneous superior mesenteric artery (SMA) dissection in a 51-year-old man. (A-B) Axial and (C) sagittal images from contrastenhanced computed tomography (CT) show crescentic hypodensity (white arrows) along the SMA and distal branches consistent with a thrombosed false lumen. No aortic dissection was present. Note that the dissection starts along the anterior wall (arrowhead) of the SMA. There were no CT signs of bowel ischemia.

thrombosis and thrombophlebitis may propagate from acute inflammatory conditions of the bowel, including appendicitis and diverticulitis (-Fig. 13). ${ }^{60,61}$

An occlusive thrombus will tend to expand the vein lumen and is more likely to cause ischemia than a nonocclusive clot. Superimposed ischemia is suspected when MDCT shows bowel wall thickening with ill-defined margins, bowel luminal distension, thickened and hazy mesentery, and ascites due to venous congestion (see - Fig. 12). ${ }^{57}$ It may be difficult to differentiate a bowel inflammatory condition causing thrombosis from a thrombosis causing bowel ischemia, due to shared nonspecific findings of wall thickening, adjacent fat stranding, and mucosal hyperenhancement.

\section{Strangulating Bowel Obstruction, Closed Loop Obstruction, and Volvulus}

Decreased blood flow may complicate mechanical bowel obstruction ("strangulated bowel obstruction"), closed loop obstruction, or volvulus, leading to AMI. Ischemia in these settings can occur by two mechanisms. Progressive luminal dilation secondary to complete bowel obstruction can cause decreased intramural blood flow directly, resulting in AMI. Alternatively, kinking or extrinsic compression of the mesenteric vasculature secondary to volvulus or closed loop obstruction can also compromise venous outflow initially and arterial inflow subsequently. In the later mechanism, the imaging features are often primarily of venous occlusion. Intramural hemorrhage related to venous congestion is
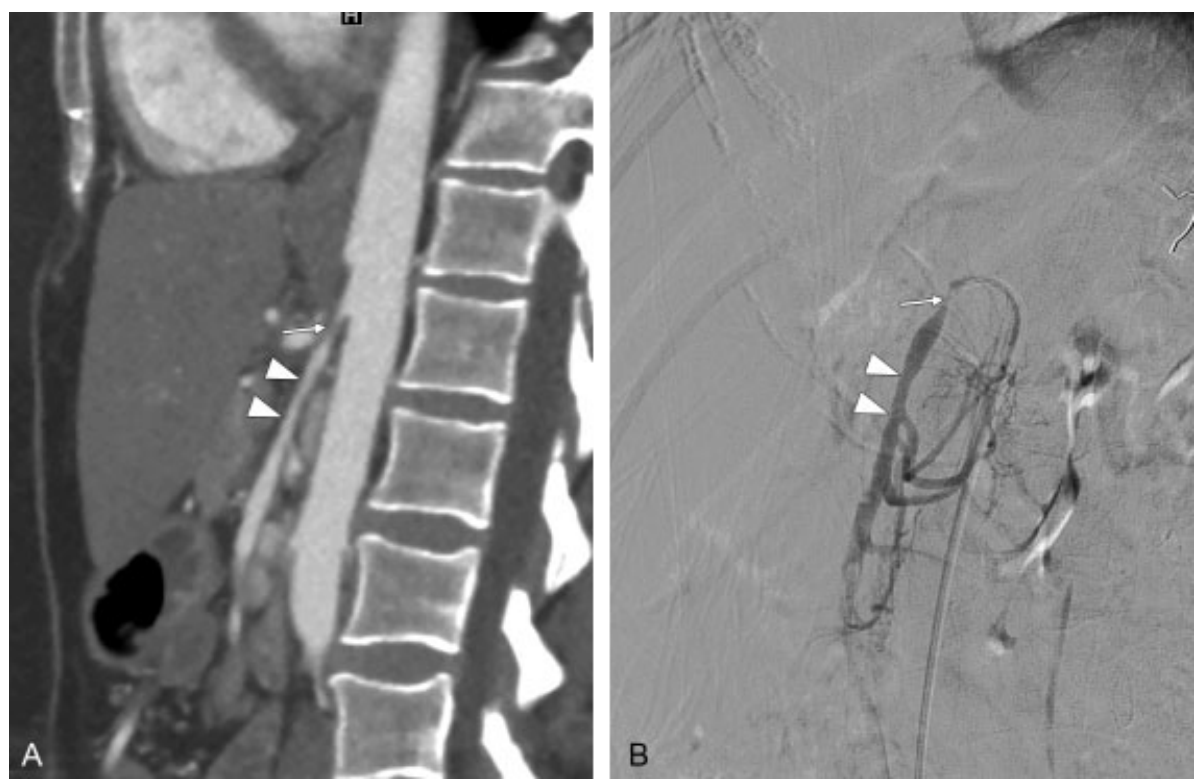

Fig. 9 Takayasu arteritis causing superior mesenteric artery (SMA) stenosis in a 34-year-old woman. The patient complained of chronic abdominal pain suggestive of chronic mesenteric ischemia. (A) Sagittal image from contrast-enhanced computed tomography and (B) subsequent digital subtraction angiogram with selective injection of the SMA show high-grade stenosis of the proximal SMA (arrow) followed by a long segment of mild narrowing (arrowheads). Similar findings were also seen in the left subclavian artery and celiac axis (not shown). There was no vascular wall thickening or enhancement, suggesting this was chronic and did not reflect active inflammation. 

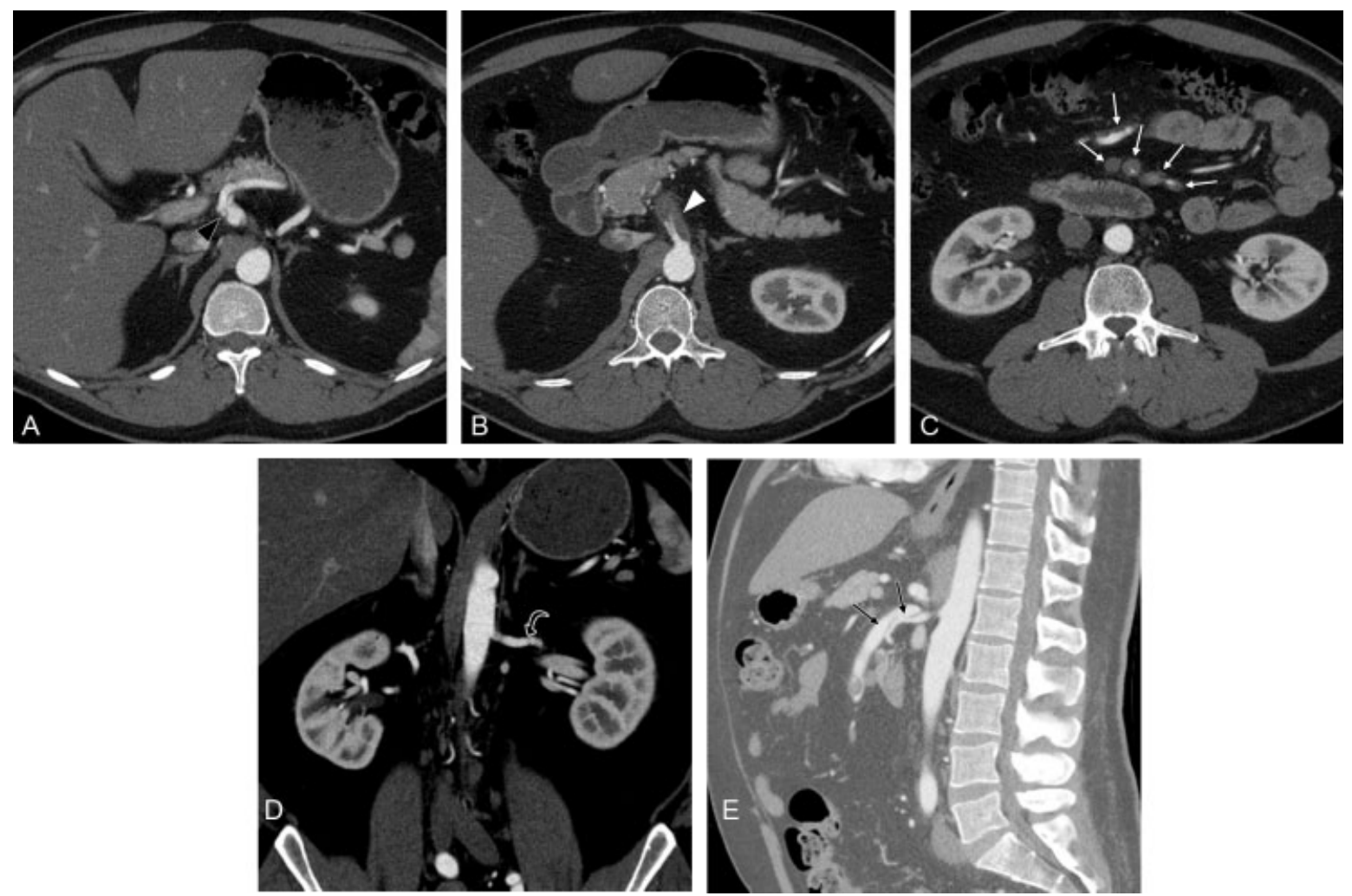

Fig. 10 Multiple intra-abdominal dissecting aneurysms in a 39-year-old man with a presumptive diagnosis of segmental arterial mediolysis. (AB) Axial images from contrast-enhanced computed tomography angiography (CTA) show aneurysmal dilation and dissection of the celiac axis (black arrowhead) and aneurysmal dilation of the proximal superior mesenteric artery (SMA) (white arrowhead) with eccentric noncalcified hypodensity narrowing the lumen that was initially indeterminate for thrombosed dissection versus solid vascular wall thickening. (C) More distal image from the same CTA shows that the eccentric wall thickening or thrombosed dissection extends into multiple SMA branches (small arrows), and in some, the lumen appears occluded. Despite this, no acute mesenteric ischemia was suspected clinically or on imaging. (D) Coronal image from the same CTA shows mild irregularity of the left renal artery (curved black arrow). (E) Sagittal image from a follow-up CTA shows evolution of SMA dissection with recanalization of the false lumen (black arrows).

reportedly common, though may be difficult to detect on postcontrast MDCT. ${ }^{62}$

Differentiation of simple bowel obstruction, which may be treated nonoperatively in select patients, from mesenteric volvulus or closed loop obstruction is important, particularly if signs of AMI are not yet present. Strangulation is unlikely in the absence of mesenteric fluid. ${ }^{63}$ Volvulus can be idiopathic or secondary to postoperative adhesions, hernia, or congenital malrotation. ${ }^{64,65}$ Closed loop obstruction may occur as a complication of volvulus, or without volvulus due to adhesions or a small-necked hernia. Twisting or constriction of the mesentery compresses first the mesenteric venous outflow and later the arterial inflow, causing ischemia and eventually infarct. ${ }^{66}$ On MDCT, the venous cut-off sign reflects SMV occlusion at the point of torsion from volvulus or compression from closed loop obstruction. ${ }^{67}$ Another MDCT sign more specific for volvulus is the whirl sign, which reflects swirling of mesenteric fat and vessels (- Fig. 14). ${ }^{65}$ The whirl sign is most apparent perpendicular to the axis of rotation, often on coronal or sagittal images, and on maximum intensity projection reconstructions, and if present in an obstructed patient, increases the likelihood of requiring surgery by 25 -fold. ${ }^{68}$ Two adjacent loops of focally decompressed bowel, each with a triangular appearance in cross- section, with an intervening U-shaped segment of fluiddilated bowel, often with upstream bowel dilation, also favor volvulus or closed loop obstruction (- Fig. 15) ${ }^{64}$

\section{Nonocclusive Mesenteric Ischemia}

Approximately $16 \%$ of cases of mesenteric ischemia occur without arterial or venous occlusion. ${ }^{29}$ This condition is known as NOMI and causes ischemia due to severe and sustained mesenteric vasoconstriction. Critically ill patients with a circulatory failure from shock (from sepsis, hypovolemia, hemorrhage, or cardiogenic), or with splanchnic vasoconstriction from use of pressors or vasoactive drugs (such as digoxin and ergotamine), are at risk of NOMI. ${ }^{69,70}$ Splanchnic autoregulation normally maintains mesenteric perfusion pressure in response to an abrupt drop in blood pressure, ${ }^{12}$ but below a certain threshold, this physiologic autoregulation fails. ${ }^{71}$ NOMI is particularly problematic and lethal because the vasoactive drugs typically used to support systemic circulation risk further compromise of the mesenteric circulation.

Classically, the diagnosis of NOMI depended on characteristic findings on digital subtraction angiography, which will be discussed further in Chapter 8 of this issue. ${ }^{72,73}$ On 


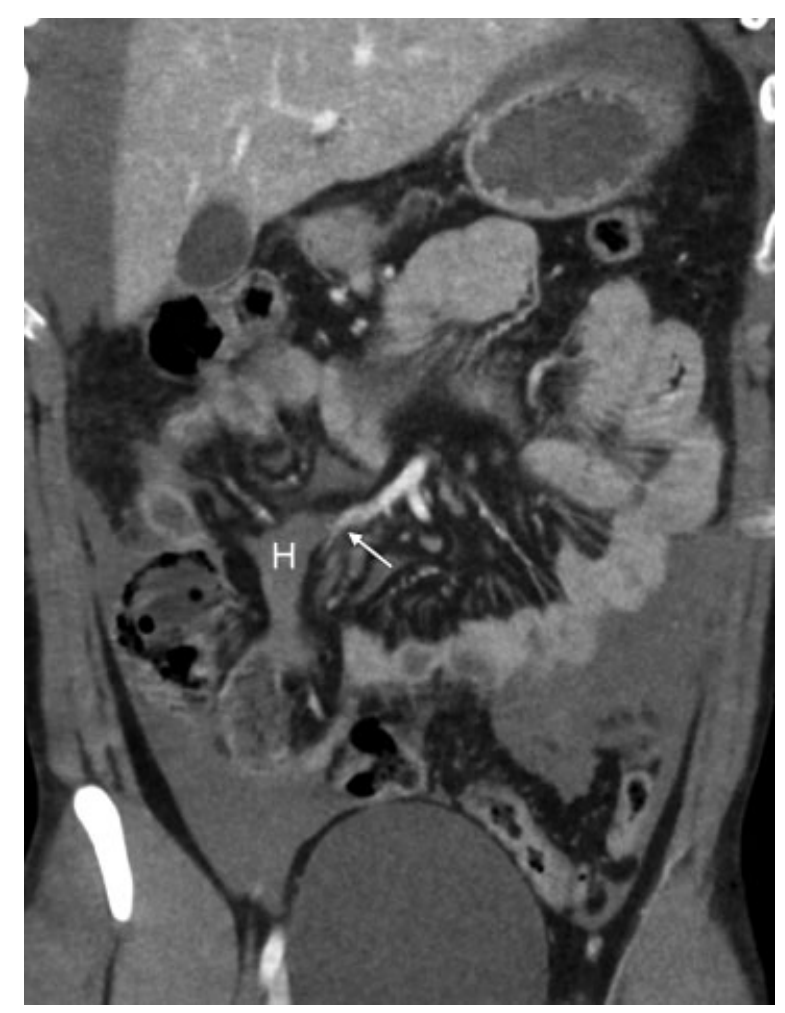

Fig. 11 Mesenteric laceration in a 20-year-old man with multiple injuries from high-speed rollover motor vehicle crash. Coronal image from contrast-enhanced computed tomography shows hemoperitoneum and a triangular mesenteric hematoma $(H)$ adjacent to the superior mesenteric artery and superior mesenteric vein (arrow), which were focally irregular at this location. Mesenteric injury was confirmed and repaired at laparotomy.

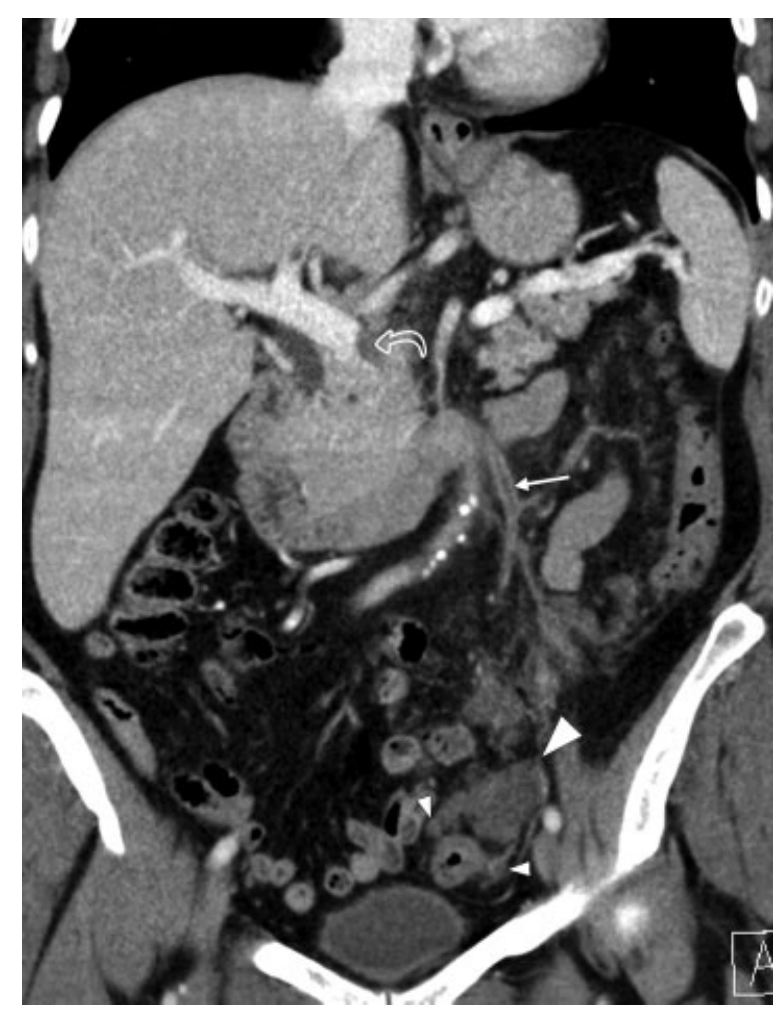

Fig. 13 Inferior mesenteric vein (IMV) thrombophlebitis secondary to sigmoid diverticulitis in a 63-year-old woman. Coronal contrastenhanced computed tomography in venous phase demonstrates inflamed sigmoid diverticula (small arrowheads) and a pericolic left lower quadrant abscess (large arrowhead). There is thrombosis of the IMV (arrow) with wall enhancement suggesting thrombophlebitis. There is also bland thrombus in the splenic-portal vein confluence (curved arrow). No evidence of mesenteric ischemia was found.
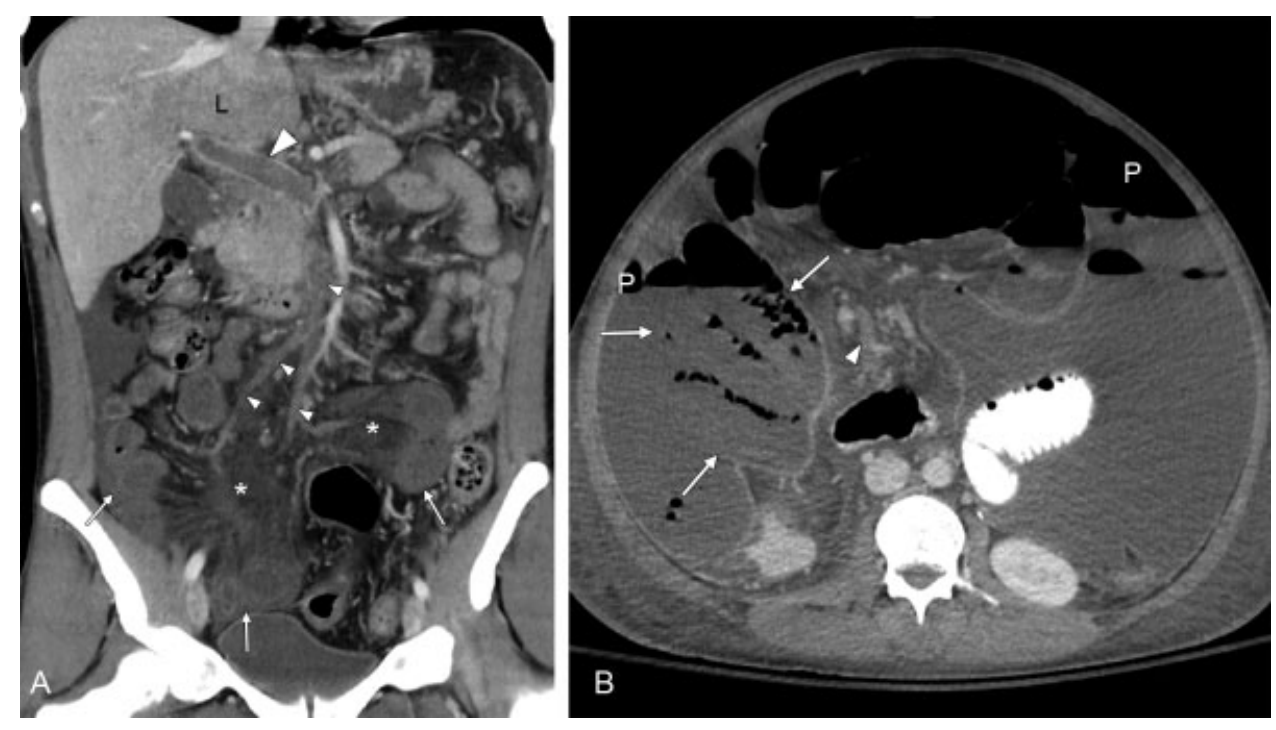

Fig. 12 Extensive portomesenteric venous thrombosis in a 26-year-old man with a history of inflammatory bowel disease. (A) Coronal image from venous phase contrast-enhanced computed tomography (CT) shows extensive thrombosis of the superior mesenteric vein trunk and branches (small arrowheads) and the main portal vein (large arrowhead). There was evidence of venous congestion of the small bowel including wall thickening and hypoenhancement (arrows) and mesenteric congestion $\left({ }^{*}\right)$. There is also regional perfusion change in the central liver (L). He had no clinical evidence of bowel compromise at presentation, and was managed with anticoagulation, catheter-directed thrombolysis, and transjugular intrahepatic portosystemic shunt (TIPS). However, he developed sudden clinical deterioration 2 weeks later, and (B) repeat contrast-enhanced CT showed persistent partial mesenteric venous thrombosis (small arrowhead), free air (P) and loculated intraperitoneal fluid reflecting peritonitis, and pneumatosis of nonenhancing right lower quadrant small bowel loops (arrows). Thirty centimeters of frankly necrotic bowel were resected at laparotomy. 

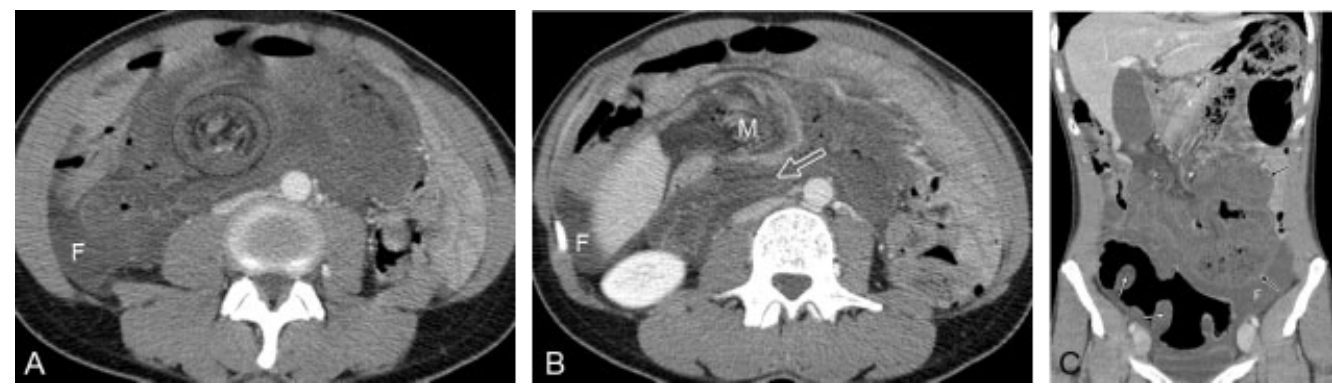

Fig. 14 Acute midgut volvulus in a 45-year-old woman with congenital malrotation. After presenting with acute abdominal pain and vomiting, she underwent a contrast-enhanced venous phase computed tomography. (A) Axial image through the mid abdomen shows a swirl sign (dashed circle) reflecting the twisting of the mesenteric vessels. (B) More superiorly, the small bowel is seen sweeping behind (open arrow) the mesentery (M). (C) Coronal reconstruction shows hypoenhancement and marked edema of the small bowel (black arrows) and cecum (white arrows), which was concerning for ischemia. A small amount of intraperitoneal free fluid (F) is seen. The patient was taken for emergent laparotomy, which confirmed twisting of the small bowel behind her mobile cecum and ascending colon. The bowel was boggy but pink and healthy, and reperfused well after detwisting, obviating the need for resection.
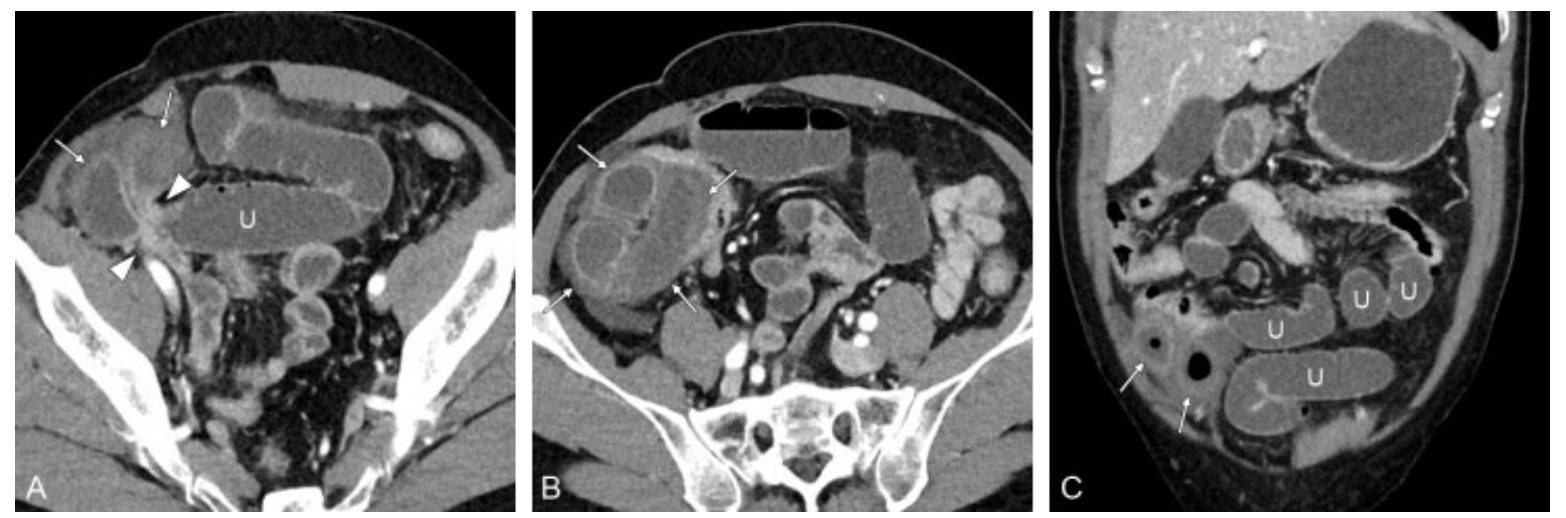

Fig. 15 Bowel ischemia from closed loop obstruction in a 67-year-old man. (A-B) Axial and (C) coronal images from contrast-enhanced computed tomography show two adjacent transition points (arrowheads) in the right lower quadrant, with dilation, wall thickening, and hypoenhancement of the intervening bowel segment (arrows), and upstream dilation (U) of additional small bowel loops that did not demonstrate evidence of ischemia. An internal hernia related to a prior history of appendectomy was confirmed at laparotomy, and $30 \mathrm{~cm}$ of ischemic mid-ileum were resected.
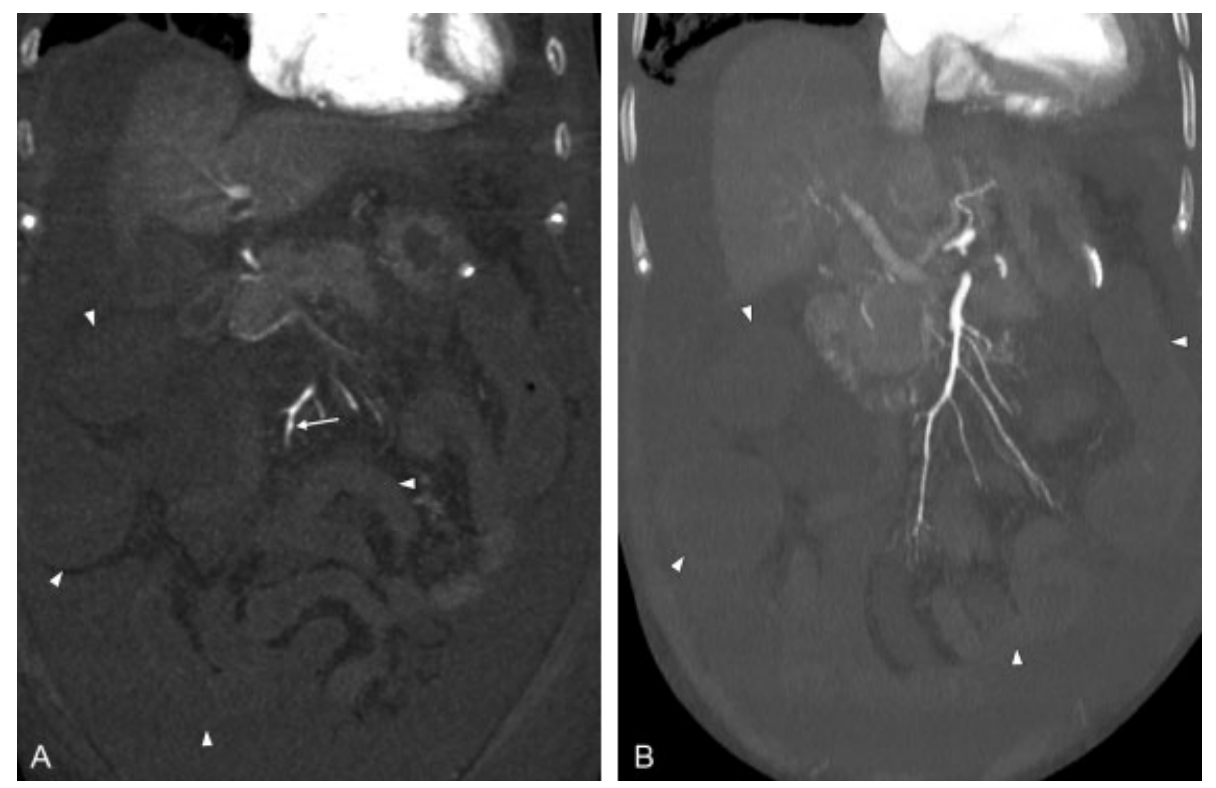

Fig. 16 Nonocclusive mesenteric ischemia in a 76-year-old woman with multiorgan failure, disseminated intravascular coagulation, and hemorrhagic shock. (A) Thin and (B) thick coronal maximum intensity projection (MIP) computed tomography angiography images through the abdomen show diffuse hypoenhancement of bowel loops (arrowheads) and irregular beaded appearance of the superior mesenteric artery (arrow) without vascular occlusion. Pruning of the peripheral visceral arcade is also evident on the thick MIP image. 
MDCT, signs of bowel ischemia are present without apparent macroscopic vascular occlusion or high-grade stenosis. ${ }^{74}$ Classic angiographic findings may be seen on CTA in some patients, including irregular SMA (-Fig. 16) and/or visceral arcade narrowing and poor intramural vascular opacification. ${ }^{75}$ MDCT reportedly has high sensitivity but low specificity for NOMI. ${ }^{74}$ In general, however, NOMI remains a diagnosis of exclusion in at-risk patients undergoing MDCT.

\section{Conclusion}

AMI is a life-threatening condition requiring a high level of clinical suspicion, a prompt diagnosis, and appropriate intervention. While generally thought to be rare, AMI is actually not uncommon in elderly patients. The various etiologies of AMI can usually be differentiated using arterial and venous phase abdominal MDCT, expediting triage of the patient to the appropriate endovascular or surgical therapy. The most common causes of AMI are SMA embolization, most often cardiogenic in source, and arterial occlusion from severe atherosclerotic disease involving both the SMA ostium and other mesenteric arteries. NOMI in critically ill hypotensive patients results in MDCT findings of ischemia without macroscopic vascular occlusion but possibly with subtle vascular findings more classically described for angiography. Bowel ischemia from venous outflow obstruction may complicate MVT. MDCT is also able to identify additional less common causes of AMI including dissection, traumatic mesenteric vascular injuries, noninflammatory vasculopathy, vasculitis, and volvulus, closed loop obstruction, and strangulating bowel obstruction.

\section{Conflict of Interest}

None.

\section{References}

1 Brandt LJ, Boley SJ; American Gastrointestinal Association. AGA technical review on intestinal ischemia. Gastroenterology 2000; 118(05):954-968

2 Kougias P, Lau D, El Sayed HF, Zhou W, Huynh TT, Lin PH. Determinants of mortality and treatment outcome following surgical interventions for acute mesenteric ischemia. J Vasc Surg 2007;46(03):467-474

3 Yamada K, Saeki M, Yamaguchi T, et al. Acute mesenteric ischemia. CT and plain radiographic analysis of 26 cases. Clin Imaging 1998; 22(01):34-41

4 Yikilmaz A, Karahan OI, Senol S, Tuna IS, Akyildiz HY. Value of multislice computed tomography in the diagnosis of acute mesenteric ischemia. Eur J Radiol 2011;80(02):297-302

5 van den Heijkant TC, Aerts BA, Teijink JA, Buurman WA, Luyer MD. Challenges in diagnosing mesenteric ischemia. World J Gastroenterol 2013;19(09):1338-1341

6 Kärkkäinen JM, Lehtimäki TT, Manninen H, Paajanen H. Acute mesenteric ischemia is a more common cause than expected of acute abdomen in the elderly. J Gastrointest Surg 2015;19(08):1407-1414

7 Evennett NJ, Petrov MS, Mittal A, Windsor JA. Systematic review and pooled estimates for the diagnostic accuracy of serological markers for intestinal ischemia. World J Surg 2009;33(07):1374-1383

8 Gourley EJ, Gering SA. The meandering mesenteric artery: a historic review and surgical implications. Dis Colon Rectum 2005;48(05):996-1000
9 Walker TG. Mesenteric vasculature and collateral pathways. Semin Intervent Radiol 2009;26(03):167-174

10 Tilsed JVT, Casamassima A, Kurihara $\mathrm{H}$, et al. ESTES guidelines: acute mesenteric ischaemia. Eur J Trauma Emerg Surg 2016;42 (02):253-270

11 Wiesner W, Khurana B, Ji H, Ros PR. CT of acute bowel ischemia. Radiology 2003;226(03):635-650

12 Reilly PM, Wilkins KB, Fuh KC, Haglund U, Bulkley GB. The mesenteric hemodynamic response to circulatory shock: an overview. Shock 2001;15(05):329-343

13 Angelelli G, Scardapane A, Memeo M, Stabile Ianora AA, Rotondo A. Acute bowel ischemia: CT findings. Eur J Radiol 2004;50(01):37-47

14 Salsano G, Salsano A, Sportelli E, et al. What is the best revascularization strategy for acute occlusive arterial mesenteric ischemia: systematic review and meta-analysis. Cardiovasc Intervent Radiol 2018;41(01):27-36

15 Treskes N, Persoon AM, van Zanten ARH. Diagnostic accuracy of novel serological biomarkers to detect acute mesenteric ischemia: a systematic review and meta-analysis. Intern Emerg Med 2017;12(06):821-836

16 Oliva IB, Davarpanah AH, Rybicki FJ, et al. ACR appropriateness criteria ${ }^{\circledR}$ imaging of mesenteric ischemia. Abdom Imaging 2013; 38(04):714-719

17 Menke J. Diagnostic accuracy of multidetector CT in acute mesenteric ischemia: systematic review and meta-analysis. Radiology 2010;256(01):93-101

18 Kirkpatrick ID, Kroeker MA, Greenberg HM. Biphasic CT with mesenteric CT angiography in the evaluation of acute mesenteric ischemia: initial experience. Radiology 2003;229(01):91-98

19 Blachar A, Barnes S, Adam SZ, et al. Radiologists' performance in the diagnosis of acute intestinal ischemia, using MDCT and specific CT findings, using a variety of CT protocols. Emerg Radiol 2011;18(05):385-394

20 Wiesner W, Hauser A, Steinbrich W. Accuracy of multidetector row computed tomography for the diagnosis of acute bowel ischemia in a non-selected study population. Eur Radiol 2004; 14(12):2347-2356

21 Lehtimäki TT, Kärkkäinen JM, Saari P, Manninen H, Paajanen H, Vanninen R. Detecting acute mesenteric ischemia in CT of the acute abdomen is dependent on clinical suspicion: review of 95 consecutive patients. Eur J Radiol 2015;84(12):2444-2453

22 Barmase M, Kang M, Wig J, Kochhar R, Gupta R, Khandelwal N. Role of multidetector CT angiography in the evaluation of suspected mesenteric ischemia. Eur J Radiol 2011;80(03):e582-e587

23 Potretzke TA, Brace CL, Lubner MG, Sampson LA, Willey BJ, Lee FTJ. Early small-bowel ischemia: dual-energy CT improves conspicuity compared with conventional CT in a swine model. Radiology 2014; $\cdots: 140875$; [ Epub ahead of print]

24 Barra L, Kanji T, Malette J, Pagnoux C; CanVasc. Imaging modalities for the diagnosis and disease activity assessment of Takayasu's arteritis: a systematic review and meta-analysis. Autoimmun Rev 2018;17(02):175-187

25 Chou CK, Mak CW, Tzeng WS, Chang JM. CT of small bowel ischemia. Abdom Imaging 2004;29(01):18-22

26 Kärkkäinen JM, Acosta S. Acute mesenteric ischemia (part I) incidence, etiologies, and how to improve early diagnosis. Best Pract Res Clin Gastroenterol 2017;31(01):15-25

27 Kärkkäinen JM, Saari P, Kettunen HP, et al. Interpretation of abdominal CT findings in patients who develop acute on chronic mesenteric ischemia. J Gastrointest Surg 2016;20(04):791-802

28 Nuzzo A, Maggiori L, Ronot M, et al. Predictive factors of intestinal necrosis in acute mesenteric ischemia: prospective study from an intestinal stroke center. Am J Gastroenterol 2017;112(04):597-605

29 Acosta S. Epidemiology of mesenteric vascular disease: clinical implications. Semin Vasc Surg 2010;23(01):4-8

30 Mastoraki A, Mastoraki S, Tziava E, et al. Mesenteric ischemia: pathogenesis and challenging diagnostic and therapeutic modalities. World J Gastrointest Pathophysiol 2016;7(01):125-130 
31 Levine JS, Jacobson ED. Intestinal ischemic disorders. Dig Dis 1995;13(01):3-24

32 Wyers MC. Acute mesenteric ischemia: diagnostic approach and surgical treatment. Semin Vasc Surg 2010;23(01):9-20

33 Garrett HE Jr. Options for treatment of spontaneous mesenteric artery dissection. J Vasc Surg 2014;59(05):1433-9.e1, 2

34 Jung SC, Lee W, Park EA, Jae HJ, Chung JW, Park JH. Spontaneous dissection of the splanchnic arteries: CT findings, treatment, and outcome. AJR Am J Roentgenol 2013;200(01):219-225

35 Orihashi K, Sueda T, Okada K, Imai K. Perioperative diagnosis of mesenteric ischemia in acute aortic dissection by transesophageal echocardiography. Eur J Cardiothorac Surg 2005;28(06):871-876

36 Apaydin AZ, Buket S, Posacioglu $\mathrm{H}$, et al. Perioperative risk factors for mortality in patients with acute type A aortic dissection. Ann Thorac Surg 2002;74(06):2034-2039, discussion 2039

37 Chao CP. Segmental arterial mediolysis. Semin Intervent Radiol 2009;26(03):224-232

38 Matolo NM, Albo D Jr. Gastrointestinal complications of collagen vascular diseases. Surgical implications. Am J Surg 1971;122(05): 678-682

39 Nastri MV, Baptista LP, Baroni RH, et al. Gadolinium-enhanced three-dimensional MR angiography of Takayasu arteritis. Radiographics 2004;24(03):773-786

40 Rits Y, Oderich GS, Bower TC, et al. Interventions for mesenteric vasculitis. J Vasc Surg 2010;51(02):392-400.e2

41 Kobayashi M, Kurose K, Kobata T, Hida K, Sakamoto S, Matsubara J. Ischemic intestinal involvement in a patient with Buerger disease: case report and literature review. J Vasc Surg 2003;38(01): 170-174

42 Barile-Fabris L, Hernández-Cabrera MF, Barragan-Garfias JA. Vasculitis in systemic lupus erythematosus. Curr Rheumatol Rep 2014;16(09):440

43 Ha HK, Lee SH, Rha SE, et al. Radiologic features of vasculitis involving the gastrointestinal tract. Radiographics 2000;20(03): 779-794

44 Krupski WC, Selzman CH, Whitehill TA. Unusual causes of mesenteric ischemia. Surg Clin North Am 1997;77(02):471-502

45 Chang WL, Yang YH, Lin YT, Chiang BL. Gastrointestinal manifestations in Henoch-Schönlein purpura: a review of 261 patients. Acta Paediatr 2004;93(11):1427-1431

46 Grayson PC, Maksimowicz-McKinnon K, Clark TM, et al; Vasculitis Clinical Research Consortium. Distribution of arterial lesions in Takayasu's arteritis and giant cell arteritis. Ann Rheum Dis 2012; 71(08):1329-1334

47 Pillai AK, Iqbal SI, Liu RW, Rachamreddy N, Kalva SP. Segmental arterial mediolysis. Cardiovasc Intervent Radiol 2014;37(03): 604-612

48 Asensio JA, Berne JD, Chahwan S, et al. Traumatic injury to the superior mesenteric artery. Am J Surg 1999;178(03):235-239

49 Moore EE, Cogbill TH, Jurkovich GJ, et al. Organ injury scaling. III: chest wall, abdominal vascular, ureter, bladder, and urethra. J Trauma 1992;33(03):337-339

50 Fullen WD, Hunt J, Altemeier WA. The clinical spectrum of penetrating injury to the superior mesenteric arterial circulation. J Trauma 1972;12(08):656-664

51 Asensio JA, Britt LD, Borzotta A, et al. Multiinstitutional experience with the management of superior mesenteric artery injuries. J Am Coll Surg 2001;193(04):354-365, discussion 365-366

52 Courcy PA, Brotman S, Oster-Granite ML, Soderstrom CA, Siegel $\mathrm{JH}$, Cowley RA. Superior mesenteric artery and vein injuries from blunt abdominal trauma. J Trauma 1984;24(09):843-845

53 Atri M, Hanson JM, Grinblat L, Brofman N, Chughtai T, Tomlinson G. Surgically important bowel and/or mesenteric injury in blunt trauma: accuracy of multidetector CT for evaluation. Radiology $2008 ; 249(02): 524-533$
$54 \mathrm{Yu}$ J, Fulcher AS, Turner MA, Cockrell C, Halvorsen RA. Blunt bowel and mesenteric injury: MDCT diagnosis. Abdom Imaging 2011;36 (01):50-61

55 Taylor GA, Fallat ME, Eichelberger MR. Hypovolemic shock in children: abdominal CT manifestations. Radiology 1987;164(02):479-481

56 Ryan MF, Hamilton PA, Sarrazin J, Chu P, Benjaminov O, Lam K. The halo sign and peripancreatic fluid: useful CT signs of hypovolaemic shock complex in adults. Clin Radiol 2005;60(05):599-607

57 Harnik IG, Brandt LJ. Mesenteric venous thrombosis. Vasc Med 2010;15(05):407-418

58 Oldenburg WA, Lau LL, Rodenberg TJ, Edmonds HJ, Burger CD. Acute mesenteric ischemia: a clinical review. Arch Intern Med 2004;164(10):1054-1062

59 Goldstein M, Quen L, Jacks L, Jhaveri K. Acute abdominal venous thromboses-the hyperdense CT sign. J Comput Assist Tomogr 2012;36(01):8-13

$60 \mathrm{Yu}$ JS, Bennett WF, Bova JG. CT of superior mesenteric vein thrombosis complicating periappendiceal abscess. J Comput Assist Tomogr 1993;17(02):309-312

61 Balthazar EJ, Gollapudi P. Septic thrombophlebitis of the mesenteric and portal veins: CT imaging. J Comput Assist Tomogr 2000; 24(05):755-760

62 Geffroy Y, Boulay-Coletta I, Jullès MC, Nakache S, Taourel P, Zins $M$. Increased unenhanced bowel-wall attenuation at multidetector CT is highly specific of ischemia complicating small-bowel obstruction. Radiology 2014;270(01):159-167

63 Millet I, Taourel P, Ruyer A, Molinari N. Value of CT findings to predict surgical ischemia in small bowel obstruction: a systematic review and meta-analysis. Eur Radiol 2015;25(06):1823-1835

64 Balthazar EJ, Birnbaum BA, Megibow AJ, Gordon RB, Whelan CA, Hulnick DH. Closed-loop and strangulating intestinal obstruction: CT signs. Radiology 1992;185(03):769-775

65 Khurana B. The whirl sign. Radiology 2003;226(01):69-70

66 Nakashima K, Ishimaru H, Fujimoto T, et al. Diagnostic performance of CT findings for bowel ischemia and necrosis in closedloop small-bowel obstruction. Abdom Imaging 2014

67 Ho YC. "Venous cut-off sign" as an adjunct to the "whirl sign" in recognizing acute small bowel volvulus via CT scan. J Gastrointest Surg 2012;16(10):2005-2006

68 Duda JB, Bhatt S, Dogra VS. Utility of CT whirl sign in guiding management of small-bowel obstruction. AJR Am J Roentgenol 2008;191(03):743-747

69 Ceppa EP, Fuh KC, Bulkley GB. Mesenteric hemodynamic response to circulatory shock. Curr Opin Crit Care 2003;9(02):127-132

70 Krejci V, Hiltebrand LB, Sigurdsson GH. Effects of epinephrine, norepinephrine, and phenylephrine on microcirculatory blood flow in the gastrointestinal tract in sepsis. Crit Care Med 2006;34 (05):1456-1463

71 Saba L, Mallarini G. Computed tomographic imaging findings of bowel ischemia. J Comput Assist Tomogr 2008;32(03):329-340

72 Siegelman SS, Sprayregen S, Boley SJ. Angiographic diagnosis of mesenteric arterial vasoconstriction. Radiology 1974;112(03): 533-542

73 Trompeter M, Brazda T, Remy CT, Vestring T, Reimer P. Nonocclusive mesenteric ischemia: etiology, diagnosis, and interventional therapy. Eur Radiol 2002;12(05):1179-1187

74 Kwok HC, Dirkzwager I, Duncan DS, Gillham MJ, Milne DG. The accuracy of multidetector computed tomography in the diagnosis of non-occlusive mesenteric ischaemia in patients after cardiovascular surgery. Crit Care Resusc 2014;16(02):90-95

75 Woodhams R, Nishimaki H, Fujii K, Kakita S, Hayakawa K. Usefulness of multidetector-row CT (MDCT) for the diagnosis of non-occlusive mesenteric ischemia (NOMI): assessment of morphology and diameter of the superior mesenteric artery (SMA) on multi-planar reconstructed (MPR) images. Eur J Radiol 2010;76(01):96-102 